Titulillo: APLICACIÓN DEL PRINCIPIO DE SEÑALIZACIÓN EN UN OBJETO VIRTUAL DE APRENDIZAJE PARA ADULTOS

Aplicación del principio de señalización en un objeto virtual de aprendizaje para adultos

\author{
Carolina Avila Coral
}

Universidad Pedagógica Nacional

Esta investigación se realizó como requisito para optar por el título de Magister en

Tecnologías de la Información Aplicadas a la Educación y fue dirigida por el profesor Jaime

Ibáñez Ibáñez. 


\section{Derechos de autor}

"Para todos los efectos, declaro que el presente trabajo es original y de mi total autoría; en aquellos casos en los cuales he requerido del trabajo de otros autores o investigadores, he dado los respectivos créditos". (Artículo 42, parágrafo 2, del Acuerdo 031 del 4 de diciembre de 2007 del Consejo Superior de la Universidad Pedagógica Nacional)

\section{(c) (1) 8 (2)}

BY No SA Este trabajo de grado se encuentra bajo una Licencia Creative Commons de Reconocimiento - No comercial - Compartir igual, por lo que puede ser distribuido, copiado y exhibido por terceros si se muestra en los créditos. No se puede obtener ningún beneficio comercial y las obras derivadas tienen que estar bajo los mismos términos de licencia que el trabajo original. 


\section{RESUMEN ANALÍTICO EN EDUCACIÓN - RAE}

\begin{tabular}{||l|l||}
\hline \multicolumn{2}{|c||}{ Información General } \\
\hline Tipo de documento & Tesis de grado de maestría de investigación \\
\hline Título del documento al documento & Universidad Pedagógica Nacional. Biblioteca Central \\
aprendizaje para adultos \\
\hline Autor(es) & Avila Coral, Carolina \\
\hline Director & Ibáñez Ibáñez, Jaime \\
\hline Publicación & Bogotá. Universidad Pedagógica Nacional, 2015. 75 p. \\
\hline Unidad patrocinante & UNIVERSIDAD PEDAGÓn en un obicto NACIONAL \\
\hline Palabras claves & EDUCACIÓN PARA ADULTOS, APRENDIZAJE MULTIMEDIA, \\
& APRENDIZAJE. \\
\hline \hline
\end{tabular}

\section{Descripción}

De acuerdo con el principio de señalización (van Gog, 2014) el material multimedia es más eficaz cuando se adicionan señales que guían la atención de los estudiantes a los elementos relevantes del material, pero son pocas las investigaciones que se han realizado con objetos virtuales de aprendizaje dirigidos a una población adulta en etapa productiva.

El propósito de este trabajo de grado es determinar si la eficacia en una prueba de retención presentada por un grupo de adultos que observaron un contenido señalizado es mejor que la eficacia del grupo que vio los contenidos sin señalizar.

Los participantes fueron asignados aleatoriamente a dos grupos, un grupo en el cual el contenido tenía señalización $(\mathrm{N}=54)$ y un segundo grupo sin el uso de señalización $(\mathrm{N}=67)$. Los 
contenidos se accedían a través un aula virtual de Moodle que estuvo disponible durante cuatro semanas.

Los resultados indicaron que la señalización mejoró los resultados de una prueba de retención en adultos en el corto plazo pero no se encontraron diferencias en los resultados en una prueba realizada algunas horas después. La señalización nos mostros diferencias en los adultos que visualizaron los contenidos en varias ocasiones, pero si mostró mejoras en la retención de los adultos que visualizaron el contenido solo una vez.

\section{Fuentes}

El documento contiene 45 fuentes de las cuales se destacan:

Amadieu, F., Mariné, C., \& Laimay, C. (2011). The attention-guiding effect and cognitive load in the comprehension of animations. Computers in Human Behavior, 27(1), 36-40. http://doi.org/10.1016/j.chb.2010.05.009

De Koning, B. B., Tabbers, H. K., Rikers, R. M. J. P., \& Paas, F. (2009). Towards a Framework for Attention Cueing in Instructional Animations: Guidelines for Research and Design. Educational Psychology Review, 21(2), 113-140. http://doi.org/10.1007/s10648-0099098-7

Issa, N., Schuller, M., Santacaterina, S., Shapiro, M., Wang, E., Mayer, R. E., \& DaRosa, D. A. (2011). Applying multimedia design principles enhances learning in medical education. Medical Education, 45(8), 818-826. http://doi.org/10.1111/j.1365-2923.2011.03988.x Mayer, R. E. (2002). Cognitive Theory and the Design of Multimedia Instruction: An Example of the Two-Way Street Between Cognition and Instruction. New Directions for Teaching and Learning, 2002(89), 55-71. http://doi.org/10.1002/tl.47 


\begin{tabular}{|l}
\hline Mayer, R. E. (2014). The Cambridge Handbook of Multimedia Learning (2 edition). \\
Cambridge University Press. \\
Schweppe, J., \& Rummer, R. (2012). Long-term Multimedia Learning (pp. 196-198). \\
Presentado en In Staging Knowledge and Experience: How to Take Advantage of \\
Representational Technologies in Education and Training?, E. Vries. \\
$\quad$ Sung, E., \& Mayer, R. E. (2012). Affective impact of navigational and signaling aids to e- \\
learning. Computers in Human Behavior, 28(2), 473-483. \\
http://doi.org/10.1016/j.chb.2011.10.019
\end{tabular}

\begin{tabular}{|l}
\hline Contenidos \\
\hline Este documento se encuentra organizado en 8 capítulos en los cuales se realiza una \\
presentación del principio de señalización, se mencionan investigaciones anteriores donde se ha \\
estudiado y posteriormente se expone la metodología usada en esta investigación realizando una \\
descripción del desarrollo tecnológico utilizado. \\
El primer capítulo es la presentación de la investigación, en la cual se relacionan \\
estadísticas el uso del e-learning en Colombia y en América Latina y la importancia de este \\
estudio en población económicamente activa, se introducen los objetivos de la investigación y las \\
hipótesis. \\
En el segundo capítulo se aborda todo el marco teórico, se habla de qué es una multimedia, \\
investigaciones más relevantes realizadas sobre señalización en los últimos 10 años, destacando \\
Ee introduce la teoría cognitiva del aprendizaje multimedia y se presenta el principio de \\
señalización el cual es el objeto principal de este estudio.
\end{tabular}


que la mayoría de investigaciones se realizan sobre adultos jóvenes en etapa de estudio a

diferencia de esta investigación cuya población son adultos trabajadores.

En el cuarto capítulo se hace una descripción del desarrollo tecnológico utilizado, se describen las características del aula virtual Moodle utilizada, así como los elementos técnicos utilizados en la creación de los objetos virtuales de aprendizaje y la evaluación.

El quinto capítulo es dedicado a la metodología de la investigación, se describen los participantes, el diseño de la investigación, cómo los usuarios interactuaban con los objetos de aprendizaje, cómo se realiza la recolección de la información y los resultados obtenidos.

Los capítulos finales presentan el análisis de los resultados obtenidos para finalmente llegar a conclusiones y recomendaciones para futuras investigaciones.

\section{Metodología}

Participaron en la investigación 121 contratistas (59 hombres y 62 mujeres) de una entidad pública que estaban realizando el curso de inducción a la entidad (edad promedio 38.4 años $\mathrm{SD}=10.24)$. Los participantes fueron asignados a los grupos experimentales aleatoriamente.

El objeto virtual de aprendizaje fue presentado a los participantes en un aula virtual como un paquete SCORM, la plataforma tecnológica recopilaba la información en la medida que los participantes interactuaban con el contenido o realizaban la evaluación.

Posteriormente los datos recolectados fueron cargados en un paquete estadístico y analizados por medio de una prueba T para variables independientes (con señalización / sin señalización). Los resultados obtenidos fueron analizados teniendo en cuenta los antecedentes revisados. 


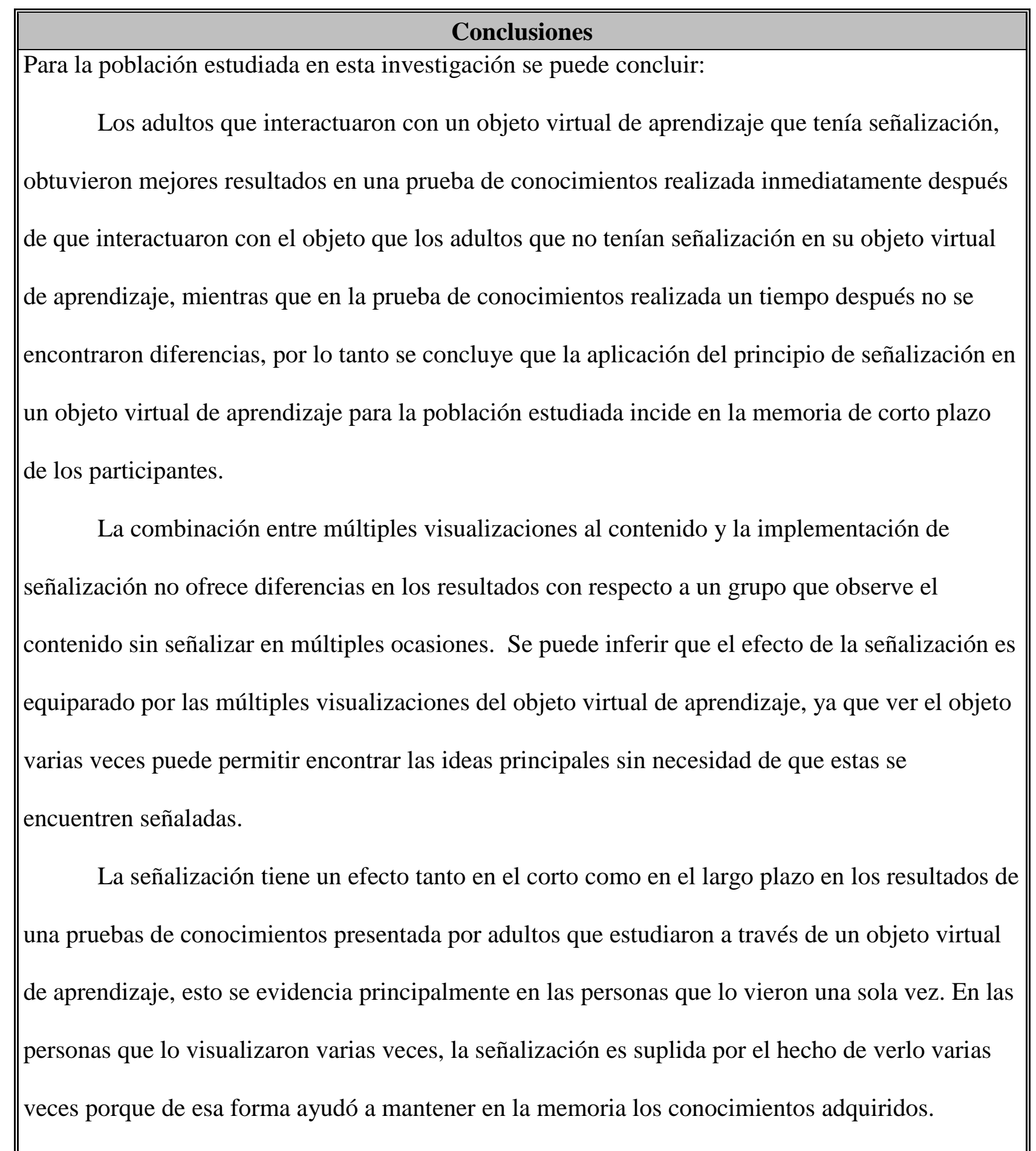




\begin{tabular}{|l|l||}
\hline Elaborado por: & Avila Coral, Carolina \\
\hline Revisado por: & Ibáñez Ibáñez, Jaime \\
\hline
\end{tabular}

\begin{tabular}{|l|l|l|l||}
\hline Fecha de elaboración del resumen & 4 & 12 & 2015 \\
\hline
\end{tabular}




\section{Tabla de Contenidos}

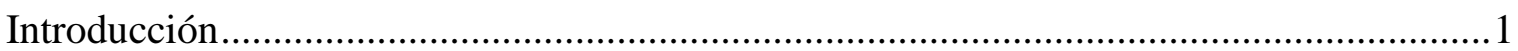

Presentación de la investigación...............................................................................

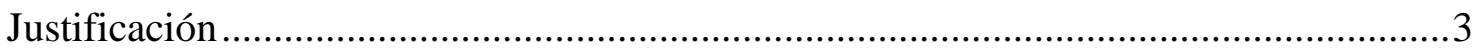

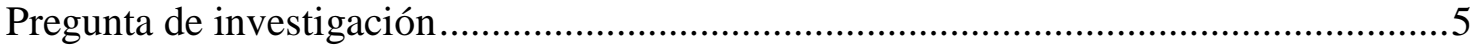

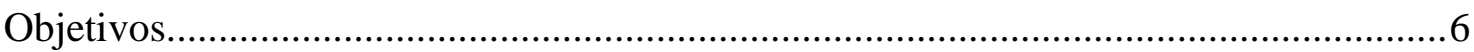

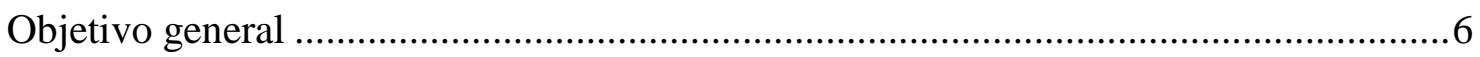

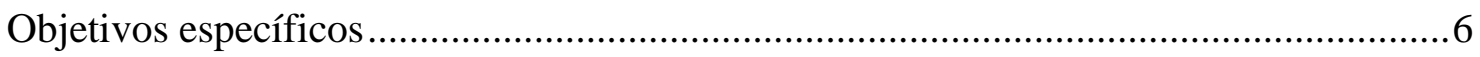

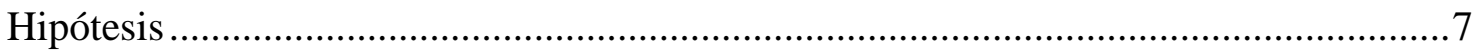

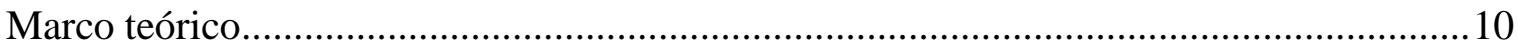

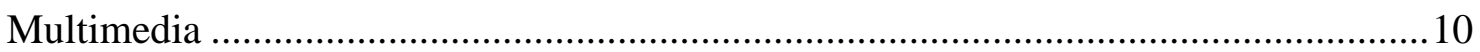

Teoría cognitiva del aprendizaje multimedia .................................................... 11

Principios del aprendizaje multimedia .......................................................... 14

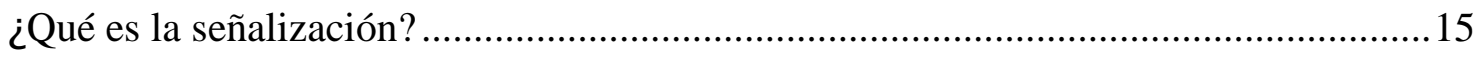

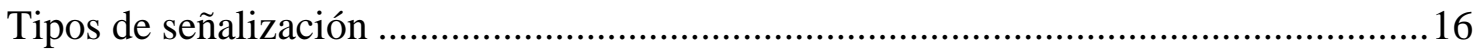

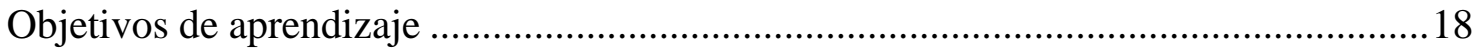

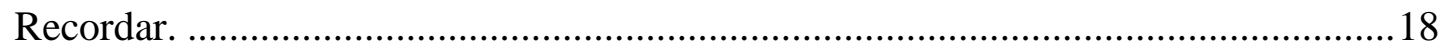

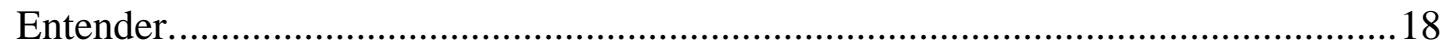

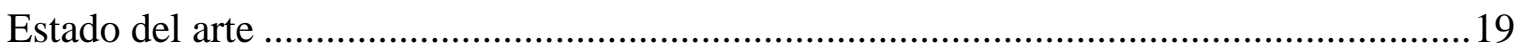


Descripción del desarrollo tecnológico ..................................................................26

Los objetos virtuales de aprendizaje.............................................................26

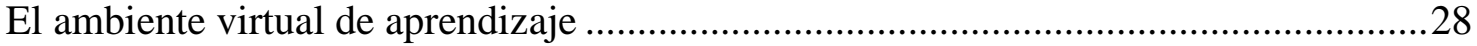

Descripción del curso virtual para el administrador...............................................28

Descripción del curso virtual para el participante .................................................... 30

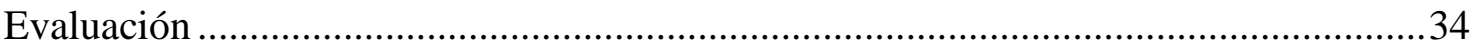

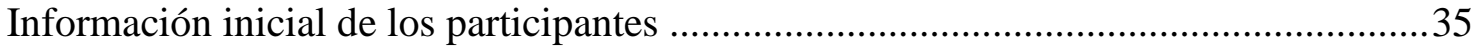

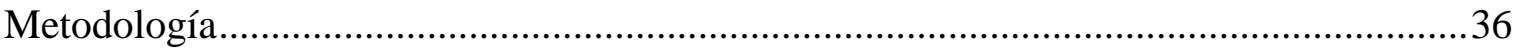

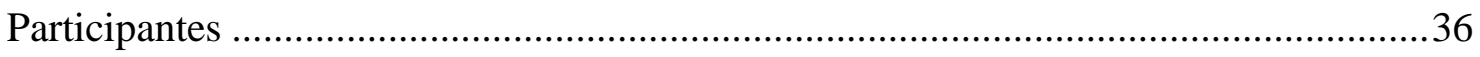

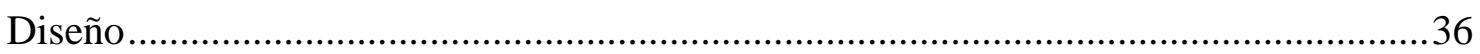

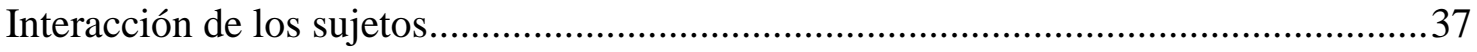

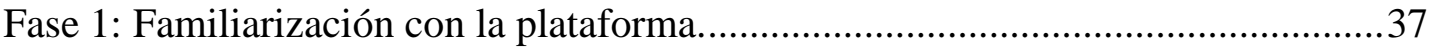

Fase 2: Presentación del curso y del contratista. ........................................................37

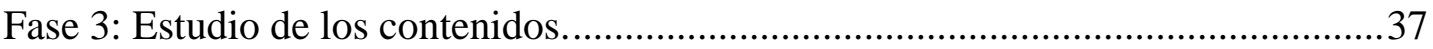

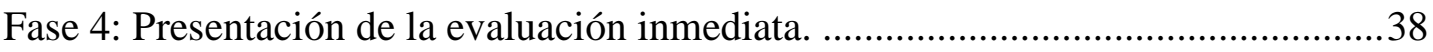

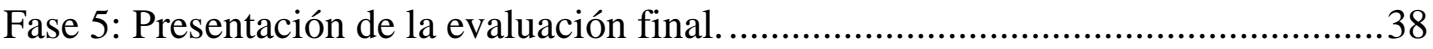

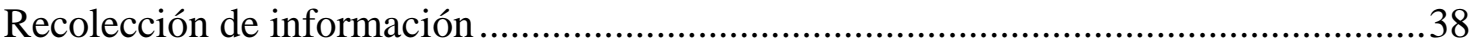

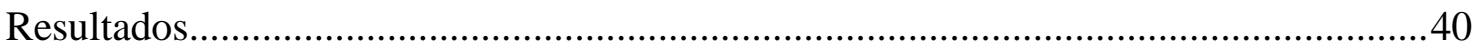

Eficacia en el primer intento...................................................................... 41

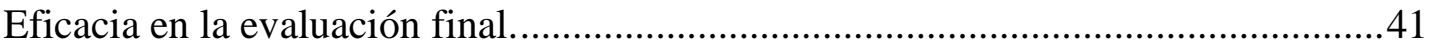




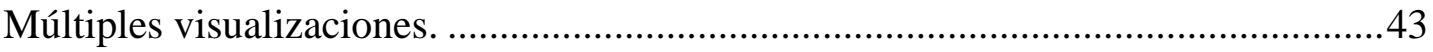

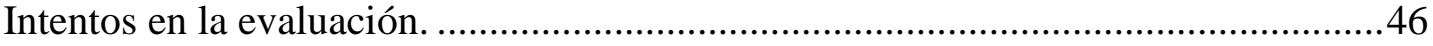

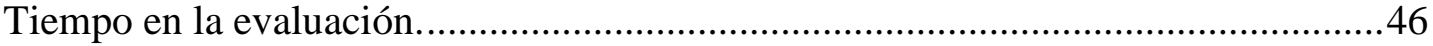

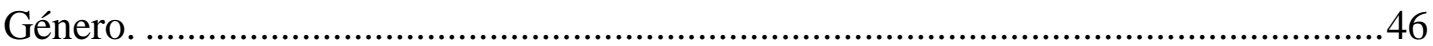

Discusión de los resultados ................................................................................4

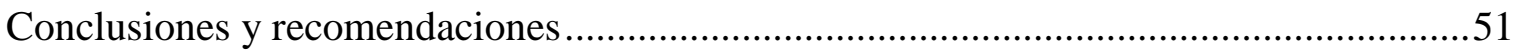

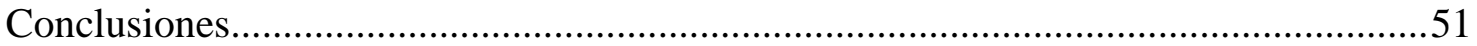

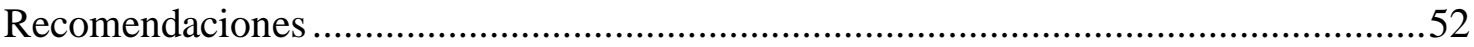

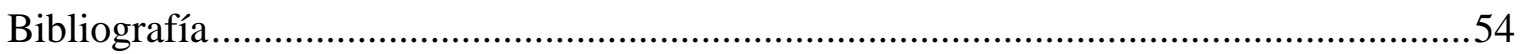

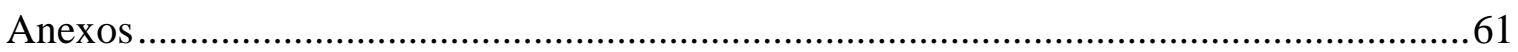

Anexo 1 Investigaciones en señalización .........................................................61

Anexo 2 Visualización del curso virtual en Moodle ..............................................62 


\section{Lista de Tablas}

Tabla 1. Principios del aprendizaje multimedia

Tabla 2. Participantes por rango de edad.

Tabla 3. Comparación de la eficacia en el primer intento

Tabla 4. Comparación de la eficacia en la evaluación final.....

Tabla 5. Correlación de la eficacia entre el primer intento y la evaluación final

Tabla 6. Eficacia en la evaluación inmediata según el número de visualizaciones

Tabla 7. Eficacia en la evaluación cuando se vio el contenido una vez.....

Tabla 8. Eficacia en la evaluación cuando se vio el contenido varias veces.....

Tabla 9. Investigaciones en señalización entre 2007 - 2015 por país de origen 


\section{Lista de Figuras}

Figura 1. Investigaciones por edad de los participantes, año de publicación y país

Figura 2 Presentación de una página con señalización

Figura 3 Presentación de una página sin señalización

Figura 4 Imagen que identifica un módulo del curso virtual.......................................28

Figura 5 Vista de las actividades por parte del tutor del curso.....................................29

Figura 6 Configuración de la restricción de acceso a un contenido .................................29

Figura 7 Configuración de las opciones de finalización de la actividad ...........................30

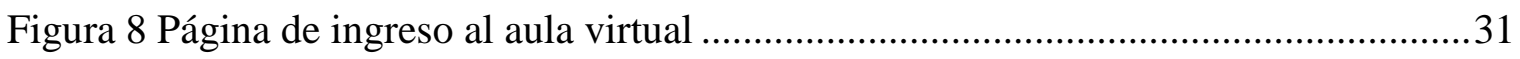

Figura 9 Visualización de actividades cuando no han sido finalizadas..............................32

Figura 10 Visualización de actividades cuando han sido finalizadas...............................32

Figura 11 Página de introducción a la evaluación..........................................................33

Figura 12 Contador de tiempo en la evaluación .............................................................33

Figura 13 Pregunta de selección múltiple en la evaluación ............................................33

Figura 14 Reporte de acceso a un paquete SCORM ..................................................39

Figura 15 Visualización del curso virtual en Moodle .................................................62 


\section{Introducción}

Los efectos de los principios del aprendizaje multimedia han sido estudiados en un gran número de investigaciones en todo el mundo (R. E. Mayer, 2014). De acuerdo con el principio de señalización (van Gog, 2014) el material multimedia es más eficaz cuando se adicionan señales que guían la atención de los estudiantes a los elementos relevantes del material.

El efecto de la señalización en el procesamiento cognitivo está explicado principalmente por la reducción de la búsqueda visual y la innecesaria carga asociada a localizar información relevante (De Koning, Tabbers, Rikers, \& Paas, 2009), pero son pocas las investigaciones que se han realizado con objetos virtuales de aprendizaje dirigidos a una población adulta en etapa productiva.

La señalización por color, ha sido propuesta como una alternativa de señalización que favorece el aprendizaje (Ozcelik, Karakus, Kursun, \& Cagiltay, 2009), el propósito de este estudio es determinar si la eficacia en una prueba de retención presentada por un grupo de adultos que observaron un contenido señalizado es mejor que la eficacia del grupo que vio los contenidos sin señalizar. Participaron en la investigación 121 contratistas (59 hombres y 62 mujeres) de una entidad pública que estaban realizando el curso de inducción a la entidad (edad promedio 38.4 años $\mathrm{SD}=10.24)$.

Los participantes fueron asignados aleatoriamente a dos grupos, un grupo en el cual el contenido tenía señalización ( $\mathrm{N}=54)$ y un segundo grupo sin el uso de señalización (N=67). Los contenidos se accedían a través un aula virtual de Moodle que estuvo disponible durante cuatro semanas. Los participantes elegían en qué momento realizaban la visualización de los contenidos y la presentación de las evaluaciones. 
Los resultados indicaron que la señalización mejoró la eficacia de los adultos en una prueba de retención en el corto plazo siendo consistente con los resultados de otras investigaciones realizadas con jóvenes (Boucheix \& Lowe, 2010 Exp. 1a; Issa et al., 2011; Jamet, Gavota, \& Quaireau, 2008; Naumann, Richter, Flender, Christmann, \& Groeben, 2007; Ozcelik et al., 2009), pero no se encontraron diferencias en los resultados en una prueba realizada algunas horas después. A su vez se pudo determinar que la señalización mejora la eficacia cuando los estudiantes visualizan los contenidos una sola vez, pero no genera diferencias en la eficacia entre estudiantes que visualizan el contenido múltiples veces lo cual son resultados diferentes a los que se habían encontrado investigaciones previas (Amadieu, Mariné, \& Laimay, 2011).

Son necesarias futuras investigaciones en la aplicación del principio de señalización en adultos para determinar si la señalización puede implicar efectos no solo en la retención sino también en la transferencia y la solución de problemas y para verificar el impacto de la señalización en la memoria de largo plazo cuando el estudiante visualiza los contenidos en una ocasión y en múltiples ocasiones. 


\section{Presentación de la investigación}

\section{Justificación}

El mercado del e-learning está creciendo año a año, en América Latina se espera un crecimiento del $9.7 \%$ anual hasta el año 2018 y en solo Colombia se espera un crecimiento entre el 15\% y el 20\% (OBS Business School, 2015).

La revista América Learning \& Media realizó entrevistas a 16 especialistas de 11 países diferentes para analizar las perspectivas de la industria del e-learning en el 2015, en las conclusiones sobresale la importancia que la educación virtual tiene en las empresas como una nueva modalidad de formación efectiva para satisfacer las necesidades de capacitación del talento humano (“Tendencias y desafíos para el e-learning en 2015”, 2015).

Se espera que la formación online corporativa crezca un 13\% anual hasta el 2017 (OBS Business School, 2015) por lo cual la educación de adultos en etapa laboral se convierte en un tema de interés para la comunidad académica y empresarial.

En Colombia para el año 2011, el 68\% de la población económicamente activa y que se encontraba ocupada tenía una edad superior a los 30 años (Orjuela, 2012), entonces surge la pregunta de si los principios de la teoría del aprendizaje multimedia (R. E. Mayer, 2002) pueden ser aplicados a objetos virtuales de aprendizaje para adultos.

Dentro de los principios del aprendizaje multimedia se ha seleccionado el estudio del principio de señalización, el cual aborda la fallas de los estudiantes en la extracción del material importante y los guía hacia la información de mayor relevancia (Boucheix, Lowe, Putri, \& Groff, 2013). La señalización consiste en dirigir la atención de los alumnos a partes específicas del material de aprendizaje con el fin de apoyar el aprendizaje (Amadieu et al., 2011). Estudios previos han sugerido que la señalización mejora el aprendizaje multimedia (Ozcelik, Arslan-Ari, \& Cagiltay, 2010). 
La mayoría de las investigaciones que se encuentran sobre la señalización se centran en experimentos realizados con estudiantes universitarios y muy pocas referencias se encuentran con adultos en etapa productiva. En la Figura 1 se muestra la distribución de las investigaciones encontradas en señalización que fueron publicadas en los últimos diez años; los puntos azules representan cada una de las investigaciones organizadas por edad promedio de los participantes, fecha de publicación de la investigación y país de la institución del investigador principal. En color rojo se ubica esta investigación. El detalle de las investigaciones consultadas se puede consultar en el Anexo 1.

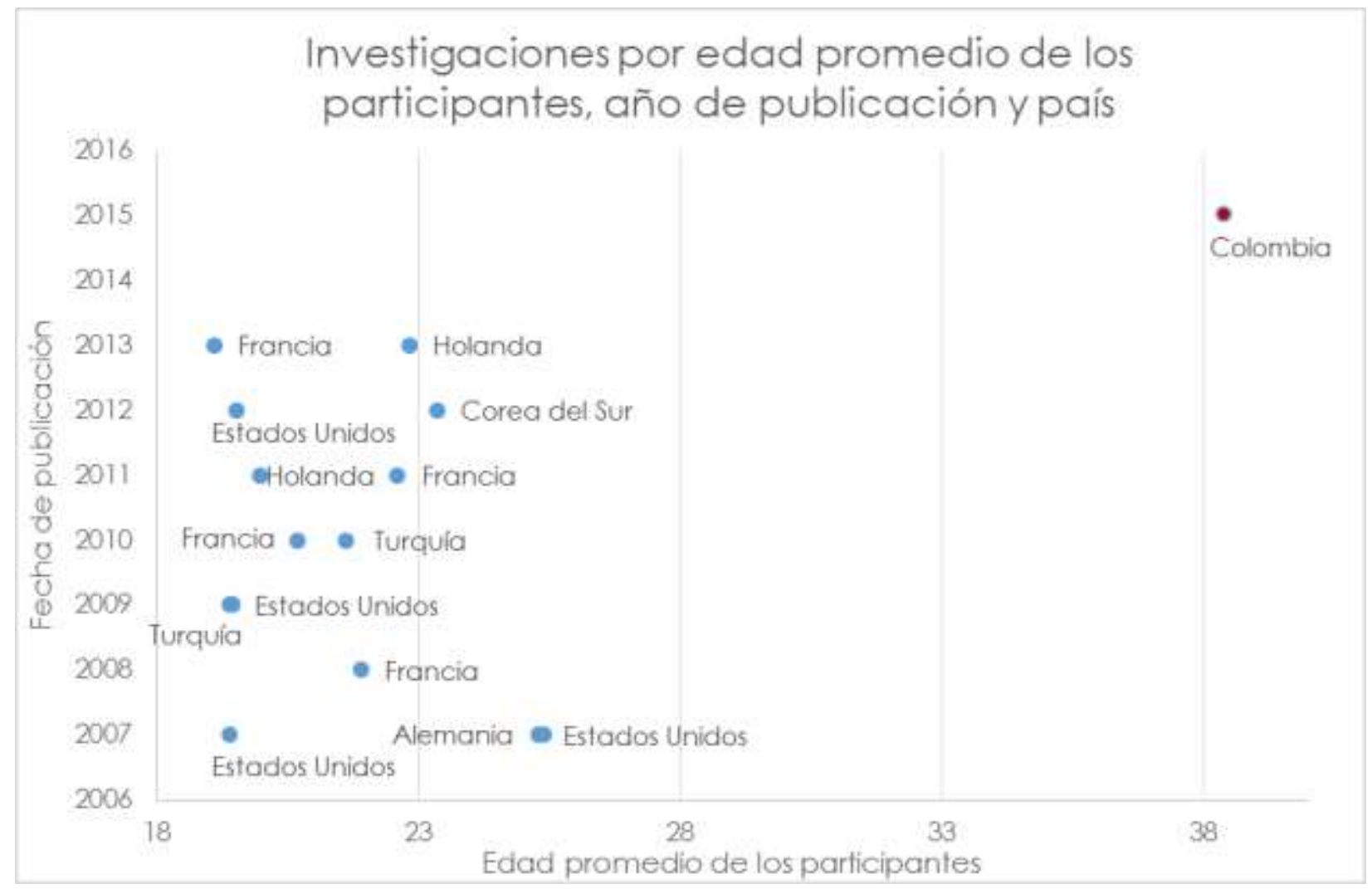

Figura 1. Investigaciones por edad de los participantes, año de publicación y país Fuente: elaboración propia

En esta investigación se busca encontrar la intersección entre el conocimiento, la instrucción y la tecnología enfocada en el aprendizaje para adultos. De todos estos escenarios, se 
trata de determinar cuáles son los recursos que pueden dar mejores resultados en el aprendizaje con la limitación de técnicas, económicas y humanas a los cuales se enfrentan las empresas y las instituciones educativas en Colombia. Esta investigación comparte las preocupaciones de varios autores (Doolittle \& Altstaedter, 2009; Kriz \& Hegarty, 2007; Mautone \& Mayer, 2007; R. E. Mayer, 2014; Naumann et al., 2007; Scheiter \& Eitel, 2015; van Gog, 2014) sobre la forma de presentar la información de manera que ayude a las personas a entender, particularmente el uso de palabras e imágenes para explicar conceptos.

Estos resultados serán de utilidad para toda la comunidad académica y las empresas comerciales que desarrollan cursos virtuales, ya que promueven principios de diseño instruccional aplicables a todos los tipos de contenidos, y dan lineamientos esenciales para que programadores, diseñadores y docentes los apliquen directamente a la creación de sus objetos virtuales de aprendizaje.

\section{Pregunta de investigación}

Teniendo en cuenta que el énfasis de esta investigación está en el principio de señalización aplicado a objetos virtuales de aprendizaje utilizados en el aprendizaje corporativo, se formula, en este proyecto, la siguiente pregunta de investigación:

¿Hay diferencias en cuanto a los resultados de una prueba de retención entre adultos que interactuaron con un objeto virtual de aprendizaje que incluye señalización y los que interactuaron en el mismo ambiente sin señalización? 


\section{Objetivos}

\section{Objetivo general}

Determinar la incidencia del principio de señalización en el aprendizaje en adultos en un ambiente virtual de aprendizaje.

\section{Objetivos específicos}

Se formulan los objetivos específicos en términos de la eficacia de los participantes en una prueba de retención, ya que será el indicador usado para determinar si el principio de señalización mejora el aprendizaje de los participantes.

- Comparar los resultados de una prueba de retención de conocimientos realizada a un grupo de adultos inmediatamente después de estudiar un objeto virtual de aprendizaje con señalización y un grupo que estudia el mismo objeto virtual sin señalización.

- Comparar los resultados en una prueba de retención de conocimientos que es realizada tiempo después de que un grupo de adultos estudia un objeto virtual de aprendizaje con señalización y un grupo que estudia el mismo objeto virtual sin señalización

- Establecer la incidencia del número de visualizaciones de un objeto virtual de aprendizaje con señalización en los resultados de una prueba de retención de conocimientos presentada por adultos. 


\section{Hipótesis}

A partir de este análisis, se presentan las siguientes predicciones que se probarán o refutarán en el presente estudio.

Hipótesis 1: Los estudiantes con señalización en el mensaje multimedia tienen mejores resultados en una prueba de conocimientos que los estudiantes a los que no se les presenta señalización.

Hipótesis 2: Los estudiantes con señalización en el mensaje multimedia tienen mejores resultados en una prueba de conocimientos cuando ha pasado un tiempo desde que estudiaron el contenido.

Hipótesis 3: La eficacia de los participantes con la condición de señalización se incrementará con un mayor número de visualizaciones de un objeto virtual de aprendizaje.

\section{Modelo pedagógico}

Para el diseño de los objetos virtuales de aprendizaje, se utilizará una aproximación cognitivista a través de la teoría de Robert Gagné(1987), que incluye las siguientes fases:

Fase de motivación. Existen dos medios para motivar a los estudiantes: explicar qué pueden hacer una vez adquirido el aprendizaje y presentar la lección de forma que atraiga su curiosidad. Al iniciar la elaboración de los objetos virtuales de aprendizaje, se realizará la presentación a los participantes de los objetivos del módulo de estudio.

Fase de adquisición. Durante esta fase debe facilitarse a los estudiantes el recuerdo, mediante indicaciones útiles, de los requisitos previos necesarios para aprender cada uno de los 
resultados del aprendizaje. El individuo reconstruye la información recibida para almacenarla en la memoria.

Previo al uso del objeto virtual de aprendizaje, se explica a los participantes como utilizar el aula virtual, como navegar los contenidos y como interactuar con los recursos.

Fase de recuerdo. Se utilizan repasos espaciados para aumentar la retención de los conocimientos adquiridos por los estudiantes.

Esto se logra a través de los elementos de baja señalización, conocidos por el estudiante como "Para recordar".

Fase de ejecución. Se presentan a los estudiantes preguntas o interrogantes diferentes para obtener sus respuestas. La importancia de esta fase consiste en que es la única manera que tienen, tanto el estudiante como el profesor, de comprobar que el aprendizaje ha sido satisfactorio.

En cada uno de los temas se presentan a los estudiantes actividades de autoevaluación para comprobar el aprendizaje. Estas actividades pueden ser preguntas de selección múltiple, falso verdadero, actividades de arrastre, entre otras. Las actividades de autoevaluación no son calificables.

Una vez finalizado el estudio de los temas, se presenta al estudiante una evaluación del módulo, la cual es calificable y presenta preguntas de comprensión relacionadas con los contenidos. 
Fase de realimentación. El estudiante conoce de forma rápida si su expectativa se ha cumplido.

En las actividades de autoevaluación, la retroalimentación indica al estudiante si ha acertado o se ha equivocado en su respuesta y cuando la respuesta fue incorrecta, explica por qué fue incorrecta.

En las actividades calificables, una vez el estudiante finaliza la evaluación, puede ver las respuestas con la solución de la evaluación. 


\section{Marco teórico}

Avances en el software y la tecnología computacional permite a los diseñadores de objetos virtuales de aprendizaje usar visualizaciones dinámicas como animaciones y video, para ayudar a los estudiantes a recordar sistemas complejos y dinámicos y recordar el material estudiado (De Koning et al., 2009).

Mayer (2002) define la multimedia como la presentación de las palabras (texto impreso o texto hablado) e imágenes (como ilustraciones, fotos, animación, video). La multimedia provee oportunidades para crear ambientes de aprendizaje más efectivos combinando varios formatos como texto, imágenes estáticas, animaciones, video y audio (Ozcelik et al., 2009).

Un reto potencial al aprender en ambientes multimediales consiste en que las exigencias de procesamiento puedan exceder la capacidad de procesamiento del sistema cognitivo, situación que llamamos sobrecarga cognitiva. Por lo tanto, conviene examinar con cuidado la relación entre las exigencias cognitivas impuestas por el ambiente de aprendizaje y los resultados de aprendizaje deseados (Moreno \& Mayer, 2007).

Esta investigación se orienta a confirmar la validez de un principio de la teoría cognitiva del aprendizaje multimedia, al someter a prueba en un ambiente de aprendizaje real, dirigido a una población adulta. Para esta investigación, un adulto es toda persona que ha sobrepasado los 21 años y que no frecuenta con dedicación plena un establecimiento de enseñanza que sea continuación de la escolaridad obligatoria (Vásquez, 1985).

\section{Multimedia}

Schnotz (2014) explica que el término multimedia tiene diferentes significados a diferentes niveles. La interpretación del término cambia cuando se mira desde un nivel tecnológico, de formato o sensorial. Se describen a continuación los posibles significados que da este autor: 
- A nivel tecnológico, multimedia significa el uso de múltiples medios de entrega como computadores, pantallas o parlantes.

- A nivel de formatos de presentación, multimedia significa el uso de diferentes formas de representación como textos e imágenes.

- A nivel de modalidades sensoriales, multimedia significa el uso de múltiples órganos sensoriales como los ojos y los oídos.

Para esta investigación, el término multimedia se utiliza teniendo en cuenta el nivel de formatos de presentación.

\section{Teoría cognitiva del aprendizaje multimedia}

El aprendizaje multimedia es aprender a partir de palabras e imágenes (R. E. Mayer, 2002). Las palabras pueden ser texto hablado o texto impreso. Las imágenes pueden ser estáticas como ilustraciones, fotografías, diagramas, gráficos o mapas, o pueden ser dinámicas como animación o video (R. E. Mayer, 2008). Ejemplos de aprendizaje multimedia incluyen actividades como observar y escuchar una animación narrada, leer un libro de texto de ciencia, jugar un videojuego educacional o asistir a una exposición con diapositivas.

El aprendizaje multimedia no necesariamente requiere una alta tecnología, es posible lograrlo desde libros impresos o pizarrones en vez del uso de pantallas de computador y se puede lograr con personas que hablan en vez de parlantes (Schnotz, 2014). Sin embargo, para esta investigación solo se tiene en cuenta el aprendizaje multimedia desde una pantalla de computador.

A partir de diversos planteamientos teóricos del ámbito de las ciencias cognitivas sobre el aprendizaje, se ha desarrollado una teoría cognitiva del aprendizaje multimedia que involucra el 
desarrollo de doce principios para la instrucción con texto e imágenes (R. E. Mayer, 2002, 2014) los cuales resultan de particular interés para el diseño instruccional en línea.

La teoría cognitiva del aprendizaje multimedia (R. E. Mayer, 2002) sugiere tres tipos diferentes de procesamiento que pueden darse en el marco de la instrucción multimedial: el procesamiento superfluo, el procesamiento esencial y el procesamiento generativo.

El primero, el procesamiento superfluo, se define como los procesos cognitivos que no son necesarios para dar sentido a la nueva información sino que, por el contrario, resultan del diseño deficiente de la tarea de aprendizaje. Por ejemplo, se obliga a los estudiantes a involucrarse en procesamiento superfluo cuando el ambiente de instrucción presenta texto y gráficas que se remiten mutuamente en páginas o pantallas de computadora separadas, lo que produce un efecto de atención visual dividida que daña el aprendizaje (Moreno \& Mayer, 2007). En este caso, el estudiante debe desperdiciar valiosa capacidad cognitiva en el proceso cognitivo de ojear entre las palabras y las imágenes.

El segundo, el procesamiento esencial, se define como los procesos cognitivos requeridos para seleccionar mentalmente la nueva información representada en la memoria operativa. Cuando el material resulta complejo y desconocido para el alumno, el volumen requerido de procesamiento esencial puede volverse abrumador. En este caso, la meta del diseño instruccional consiste en administrar el procesamiento esencial (Moreno \& Mayer, 2007).

El tercero, el procesamiento generativo, se define como la atribución de sentido a la nueva información, tal como sucede en los procesos de organizar mentalmente la nueva información en una estructura coherente e integrar las nuevas representaciones de conocimiento al conocimiento previo. Unidos, los procesamientos esencial y generativo permiten la creación de un resultado de aprendizaje significativo. Cuando los alumnos carecen de motivación, pueden fallar en producir procesamiento generativo incluso cuando disponen de capacidad cognitiva. En 
este caso, la meta del diseño instruccional consiste en promover le procesamiento generativo (Moreno \& Mayer, 2007).

La teoría cognitiva del aprendizaje multimedia se centra en el procesamiento cognitivo que tiene lugar durante el aprendizaje (R. E. Mayer, 2008). Según esta teoría, la memoria operativa, funcional o de trabajo, de capacidad limitada, utiliza conocimientos que activa desde la memoria a largo plazo, cuya capacidad es ilimitada. La información del mundo exterior que recibe a través de una fuente multimedial entra por los ojos o los oídos y se registra en la memoria sensorial. De acuerdo con la teoría cognitiva del aprendizaje multimedia, el aprendizaje significativo se produce cuando el alumno selecciona, organiza e integra, en un esfuerzo consciente, nueva información a su conocimiento previo.

Las limitaciones de la memoria de trabajo conducen a la necesidad de evitar la sobrecarga cognitiva. El esfuerzo cognitivo involucrado en comprender la nueva información en texto e imágenes es requerido para un aprendizaje exitoso porque los estudiantes necesitan hacer conexiones entre los elementos asociados de la información presentada y su base de conocimiento (Kalyuga \& Renkl, 2009).

Por lo anterior, surge la necesidad de tres tipos de metas en el diseño instruccional:

1) Reducir el procesamiento superfluo, con el fin de no recargar ni exceder la capacidad cognitiva del estudiante;

2) Gestionar el procesamiento esencial, cuando el mínimo requerido supera la capacidad cognitiva del estudiante; $y$

3) Fomentar el procesamiento generativo, en los casos en que el estudiante cuenta con capacidad de procesamiento disponible pero decide no ejercer el esfuerzo de emplearla para dar sentido al material nuevo. 


\section{Principios del aprendizaje multimedia}

Usando el texto, la ilustración y la narración en una forma eficiente podemos mejorar el proceso de aprendizaje (Ozcelik et al., 2010). Es por esto que el estudio de la teoría cognitiva del aprendizaje multimedia ha desarrollado doce principios que tienen en cuenta el tipo de procesamiento que se desea enfatizar. En la Tabla 1 se describen estos principios.

Tabla 1. Principios del aprendizaje multimedia

\begin{tabular}{cl}
\hline \multicolumn{1}{c}{ Principio } & Descripción \\
\hline Procesamiento superfluo & \\
Principio de coherencia & $\begin{array}{l}\text { Aprendizaje más profundo cuando se excluyen las } \\
\text { palabras, imágenes y sonidos irrelevantes. }\end{array}$ \\
Principio de señalización & $\begin{array}{l}\text { Aprendizaje más profundo cuando se destaca el } \\
\text { material esencial. }\end{array}$ \\
Principio de redundancia & $\begin{array}{l}\text { Aprendizaje más profundo con gráficos y narración } \\
\text { que con gráficos, narración y texto escrito. }\end{array}$ \\
$\begin{array}{c}\text { Principio de contigüidad } \\
\text { espacial }\end{array}$ & $\begin{array}{l}\text { Aprendizaje más profundo cuando el texto } \\
\text { correspondiente y la animación están cercanos entre } \\
\text { si en vez de estar alejados. }\end{array}$ \\
Principio de contigüidad & $\begin{array}{l}\text { Aprendizaje más profundo cuando imágenes y } \\
\text { palabras relacionadas se presentan simultáneamente } \\
\text { en vez de presentarse sucesivamente. }\end{array}$
\end{tabular}

\section{Procesamiento esencial}

Principio de segmentación

Aprendizaje más profundo cuando se dividen los contenidos teniendo en cuenta el ritmo de los estudiantes.

Principio de pre entrenamiento Aprendizaje más profundo cuando se presentar los conceptos clave antes de la lección.

Principio de modalidad Aprendizaje más profundo con narración e imágenes en vez de solo con imágenes y texto escrito. 


\begin{tabular}{ll}
\hline \multicolumn{1}{c}{ Principio } & Descripción \\
\hline Procesamiento generativo & \\
Principio de personalización & $\begin{array}{l}\text { Aprendizaje más profundo cuando el lenguaje } \\
\text { utilizado es coloquial en lugar de formal. }\end{array}$ \\
Principio de voz & $\begin{array}{l}\text { Aprendizaje más profundo cuando se utiliza narración } \\
\text { con voz humana y no con una voz de máquina. }\end{array}$ \\
Principio de personificación & $\begin{array}{l}\text { Aprendizaje más profundo cuando los agentes en } \\
\text { pantalla emplean gestos semejantes a los humanos. }\end{array}$ \\
Principio de imagen & $\begin{array}{l}\text { Aprendizaje más profundo cuando el agente en } \\
\text { pantalla no es una imagen estática. }\end{array}$
\end{tabular}

Traducido de (Issa et al., 2011; R. E. Mayer, 2002, 2014)

Actualmente el estudio de los principios se extiende a investigar el uso de convenciones sociales como la cortesía en el habla (McLaren, DeLeeuw, \& Mayer, 2011a, 2011b), el gesto para aumentar la motivación del estudiante (R. E. Mayer \& DaPra, 2012; Sung \& Mayer, 2012; Twyford \& Craig, 2013) y los factores motivacionales que median el aprendizaje al aumentar o disminuir el compromiso cognitivo (Moreno \& Mayer, 2007).

\section{¿Qué es la señalización?}

La señalización trabaja el procesamiento superfluo del estudiante. Se presentan a continuación definiciones de señalización que han dado algunos autores que han estudiado este principio.

El principio de señalización se refiere a que los materiales de aprendizaje multimedia se vuelven más eficaces cuando las señales guían al estudiante sobre los aspectos más relevantes del material (van Gog, 2014).

La señalización consiste en enfocarse en la información importante en cada paso del proceso (Amadieu et al., 2011). 
La señalización es un enfoque destinado a abordar el problema de las fallas en la extracción de la información al guiar a los estudiantes a información de alta relevancia (Boucheix et al., 2013).

La señalización es la manipulación de características visuales y espaciales de material instruccional con el fin de ayudar a los estudiantes en la selección de información relevante y organizar e integrar la información en una representación coherente (De Koning et al., 2009).

Para esta investigación se interpretará la señalización como señales lingüísticas, tipográficas y/o visuales que apuntan a que la estructura de un mensaje de instrucción sea más accesible a un alumno sin añadir nueva información relacionada con el contenido de este mensaje (Scheiter \& Eitel, 2015).

Las señas pueden ser medios eficaces para: (1) Guiar la atención a ubicaciones específicas (2) Organizar información (3) Integrar elementos individuales en representaciones coherentes (De Koning et al., 2009).

\section{Tipos de señalización}

Dentro de la señalización existen dos tipos de objetos a los cuales se les puede incluir señalización: lo elementos estáticos (texto e imágenes) y los elementos animados.

Para Ozcelik (2010) las formas en las cuales se puede incluir señalización en un objeto multimedia son:

- Señales tipográficas como: el subrayado, mayúsculas, cursiva, negrita y variaciones de color. Estas señales tipográficas pueden ser utilizados para la introducción de términos técnicos, dirigiendo la atención a los conceptos clave, y haciendo hincapié en la información importante. 
- Estructuración del contenido: Encabezados, títulos, señales de enumeración (por ejemplo, primero, segundo)

- Flechas: especialmente para señalar elementos importantes en imágenes y diagramas.

- Claves estructurales: guiar al estudiante a lo importante a través de conectores como por ejemplo, el problema es que, hay que señalar que), resúmenes, avances.

- Señales lingüísticas: Se refiere a modificar el elemento auditivo de animaciones y videos. Por subir o bajar la entonación para resaltar los elementos importantes.

Con respecto al uso de las flechas, estas pueden indicar la dirección del movimiento en un gráfico estático, pero en una animación su función es mostrar los aspectos clave representados en el movimiento (Boucheix \& Lowe, 2010).

La señalización en animaciones puede expandir su papel para incluir señalización de eventos y de relaciones (Boucheix et al., 2013), una forma de lograrlo es mediante un camino progresivo, es de decir, se muestra la serie de eventos como un camino con una cinta con colores, aplicados a toda la cadena causal; otra forma es con señales locales, es decir, se resaltan los elementos que participan en el evento pero no la ruta del evento, aplicado solo a los elementos con funciones importantes.

Usted puede suponer que la mejor manera de promover un aprendizaje significativo es a través de actividades con las manos (el estudiante interacciona con la presentación a través del ratón o el teclado). Sin embargo, la actividad comportamental por sí misma no garantiza un aprendizaje cognitivamente activo (R. E. Mayer, 2014). 
En esta investigación se estudia la señalización mediante mensajes instruccionales multimedia en los cuales el texto con la información relevante tiene un color diferente, los estudiantes serán comportamentalmente inactivos.

\section{Objetivos de aprendizaje}

Para Mayer (2014) hay dos tipos de objetivos de aprendizaje: recordar y entender.

Recordar. Es la habilitada para reproducir o reconocer el material presentado y es medido por una prueba de retención.

Las pruebas de retención son de dos tipos: rellamado y reconocimiento.

- Una prueba de retención de rellamado solicita al estudiante reproducir lo que se le presentó (pregunta abierta).

- Una prueba de retención de reconocimiento solicita al estudiante seleccionar qué se le presentó (selección múltiple) o juzgar si un ítem fue presentado (falso / verdadero).

Entender. Es la habilidad para construir una representación mental coherente del material presentado. Esto se ve reflejado en la capacidad de usar el material presentado en nuevas situaciones y se mide por una prueba de transferencia.

En una prueba de transferencia, los estudiantes deben resolver un problema que no fue presentado en el material, es decir, debe aplicar lo que aprendió a una nueva situación.

Para esta investigación se utilizan pruebas de retención del tipo de reconocimiento, es decir las preguntas formuladas a los participantes no serán abiertas sino que serán de selección múltiple. 


\section{Estado del arte}

Se ha seleccionado el estudio del principio de señalización, el cual ha sido investigado desde hace más de 15 años. La primera investigación encontrada que estudia el efecto de la señalización en una multimedia fue realizada en Australia por Jeung, Chandler y Sweller (1997). En esta primera investigación, los estudiantes aprendían cómo resolver problemas de geometría viendo ejemplos que se trabajaban en forma de gráficos con narración en una pantalla de computador. Destacar la información relevante en pantalla mediante elementos intermitentes generó mejores resultados en una prueba de transferencia cuando la visualización era compleja pero no cuando era simple.

El estudio de los antecedentes de esta investigación se realiza con base en las investigaciones encontradas en los últimos diez años sobre el tema, las cuales se listan en el Anexo 1 de este documento.

En los estudios realizados por Stull y Mayer (2007) los estudiantes aprendieron sobre la reproducción de las especies. Se presentaba a los estudiantes una lectura que incluía organizadores gráficos en el margen del texto con los cuales se pretendía resaltar las palabras esenciales en el texto. Los investigadores realizaron tres experimentos: el primer experimento tenía 27 organizadores gráficos, en el segundo experimento 18 organizadores gráficos fueron usados y en el tercero 10. En el primer experimento la señalización no tuvo efectos en una prueba de transferencias, mientras que en los experimentos 2 y 3 se presentó un efecto de la señalización, esto sugiere qué es la señalización debe ser utilizada con moderación (R. Mayer \& Fiorella, 2014).

En Naumann (2007), se buscó identificar si la señalización dependía de las habilidades previas de los participantes. Para determinarlo, se estudiaron dos variables independientes, una variable eran las habilidades en lectura de los participantes (bajas, altas) y la otra variable la 
señalización en el hipertexto (con señalización, sin señalización). A cada grupo se les presentó una lección acerca de la percepción visual y espacial. Un efecto de la señalización fue encontrado para los lectores con bajas habilidades en una prueba de transferencia realizada mediante un ensayo pero no se encontraron diferencias significativas para los participantes con altas habilidades en lectura.

Mautone y Mayer (2007) buscaron ir un poco más allá de la técnica de mostrar los elementos importantes con intermitencia como se hizo en las primeras investigaciones, en su investigación, los estudiantes aprendieron acerca de procesos fluviales en la geografía observando gráficas científicas que incluían señalización y no señalización. Después de ver el contenido multimedia, se le pidió a los participantes que escribiera una explicación de cada una de las gráficas, el grupo que tenía señalización género más frases relacionadas acerca de la lección que aquellos que no tenían señalización, pero no hubo diferencias entre los grupos en las frases que expresaban relación de causalidad.

En el mismo año, De Koning, Tabbers, Rikers y Pass (2007) mostraron a unos estudiantes el sistema cardiovascular humano desde una animación basada por computador que contenía señales visuales. Los estudiantes que tuvieron señalización obtuvieron un mejor desempeño en una prueba de transferencia que los estudiantes que no recibieron señalización. Una investigación posterior de los mismos investigadores (De Koning, Tabbers, Rikers, \& Paas, 2010) mostró efectos menores del uso de la señalización.

Las señales visuales son más eficaces para apoyar el procesamiento perceptual y cognitivo con imágenes estáticas que con elementos visuales dinámicos como animaciones (De Koning et al., 2009), es por esto que en esta investigación la señalización se aplicará a los contenidos estáticos y no a los contenidos animados. 
Pero no todas las investigaciones han mostrado resultados exitosos de la señalización.

Kriz y Hegarty (2007) encontraron que los estudiantes que aprendían acerca de cómo trabaja un sistema mecánico viendo una animación que contenía señalización con flechas se desempeñaron únicamente un poco mejor en pruebas de comprensión que aquellos que no recibieron señalización, sin embargo una prueba de rastreo ocular reveló que la señalización dirigía la atención del estudiante a las áreas relevantes de la animación.

En dos experimentos realizados por Moreno y Mayer (2007) unos profesores en formación aprendieron acerca de siete habilidades esenciales de los profesores viendo un video que incluía señalización y otro que no incluía señalización. El grupo con señalización no tuvo diferencias significativas del grupo que no tenía señalización en unas pruebas de transferencia.

En un estudio realizado por Jamet y cols. (2008) los estudiantes que aprendieron acerca de las bases cerebrales de la producción del lenguaje desde una narración en computador con señalización no mostraron mejores resultados en una prueba de transferencia cuando la lección incluía señalización utilizando cambios de color en los elementos.

En Doolittle y Altstaedter (2009) se mostró a los estudiantes una narración animada acerca de cómo funciona el sistema de frenos de un automóvil y no tuvieron mejor desempeño en una prueba de aprendizaje cuando la señalización fue incluida en forma de elementos clave en la en la animación.

Boucheix y Lowe (2010) realizaron un experimento en el cual los estudiantes aprendían acerca de cómo trabaja un sistema de piano por medio de animaciones que incluían cambios de color y flechas durante la presentación del funcionamiento de cada pieza. El tipo de señalización con color mostró mejores resultados en las pruebas de comprensión para el tema de kinemática y funcionamiento del piano. No se encontró ningún efecto del uso de las fechas en los resultados de las pruebas de comprensión. 
Tres años después, se realizó una investigación utilizando el mecanismo de funcionamiento del piano (Boucheix et al., 2013), realizando una innovación en la forma en que se realiza la señalización. Las formas de señalización novedosas son dos:

(1) Camino progresivo: se muestra el camino a través de una cinta con colores, aplicado a toda la cadena causal.

(2) Señales locales: se resaltan los elementos que participan en el evento pero no la ruta. Los investigadores encontraron que las ayudas que enfatizan una ruta progresiva ayudan al desempeño de la transferencia mejor que cuando las ayudas únicamente tienen una secuencia de entidades individuales que se resaltan.

Ozcelik y cols. (2010) determinaron que los estudiantes que aprendían cómo funcionaba una máquina de un Jet desde una lección multimedia basada en computador que tenía señalización a través de etiquetas de color en las ilustraciones al grupo que no tenía señalización en un prueba de transferencia.

En el año 2011, investigadores de la Universidad de Toulouse en Francia (Amadieu et al., 2011) tenían la hipótesis de que el efecto de la señalización podía verse influenciado por el número de veces en que los participantes eran expuestos más de una vez a una animación. Por medio de power point y visual basic, desarrollaron una animación que explicaba el proceso de la sinapsis. Los investigadores buscaban identificar el efecto de la señalización en la presentación de elementos aislados y también en elementos con alta interactividad. Los resultados indicaron que la retención de los elementos aislados se incrementó con el número de exposiciones en los dos grupos (con señalización y sin señalización) mientras el puntaje de la comprensión de los elementos de alta interactividad se incrementó con el número de exposiciones únicamente en la condición con señalización. 
La comprensión de los elementos de alta interactividad fue impactada por la señalización. El puntaje de la comprensión de los elementos de alta interactividad se incrementó con el número de exposiciones únicamente en la condición con señalización.

Para Rey (2012), los estudiantes que aprendían acerca de las conexiones del sistema nervioso con una simulación desarrollada por computador presentaron mejores resultados en una prueba de transferencia cuando la lección incluía señalización.

En la mayoría de investigaciones revisadas se mostró que las personas aprenden más profundamente de un mensaje multimedia cuando el texto está señalizado en vez de cuando no lo está señalizado (R. Mayer \& Fiorella, 2014). En un artículo realizado por De Koning y cols. (2009) se concluye que las señales visuales son más eficaces para apoyar el procesamiento perceptual y cognitivo con imágenes estáticas que con elementos visuales dinámicos como animaciones. Para estos autores (De Koning et al., 2009), la señalización verbal (cambiar el tono de las palabras en el audio) y las flechas de color tienen la función de guiar la atención del estudiante a la información esencial y afirman que la señalización mejora la retención del texto señalizado y facilita la aplicación de la información aprendida lo que se refleja en mejor desempeño en tareas de solución de problemas de transferencia o reducir el tiempo de solución de problemas.

Es necesario realizar más trabajo para determinar cuáles aspectos de la señalización visual son más efectivos para las funciones cognitivas. Acerca de las condiciones límite, hay evidencia preliminar de que el principio de señalización aplica fuertemente cuando: 1) los aprendices tienen bajo conocimiento en vez de alto conocimiento; 2) se usa espaciadamente en vez de excesivamente; 3) se despliega información compleja en vez de información simple (R. Mayer \& Fiorella, 2014). 
Pocas de las investigaciones encontradas prueban de forma simultánea dos principios, ese no es el caso de Crooks, Cheon, Inan, Ari y Flores (2012), quienes investigan el principio de señalización con el principio de modalidad. Las medidas dependientes consistían en una prueba de recuerdo libre, una prueba de juego, una prueba de comprensión, y una prueba de recuerdo espacial. El análisis de varianza (ANOVA) se utilizó para probar las diferencias entre las condiciones en las variables dependientes. Los resultados de este estudio revelaron un efecto modalidad inversa que los que estudian el texto escrito funcionó mucho mejor que los que estudian el texto hablado en las pruebas de recuerdo libre, la comprensión, a juego, y el recuerdo espacial. La señalización no mostró diferencias en los resultados de los grupos estudiados. Sung y Mayer (2012), estudiaron el efecto de la señalización buscando encontrar la relación con otros factores dentro del aprendizaje, para ello, los participantes fueron asignados aleatoriamente a uno de los cuatro grupos basados en un diseño 2x2. El primer factor era la presencia o ausencia de ayudas a la navegación, y el segundo factor la presencia o ausencia de señalización. Los investigadores (Sung \& Mayer, 2012) analizaron el impacto de ocho criterios de usabilidad de un ambiente de e-learning en los resultados del aprendizaje. Los criterios de usabilidad que aplicaron fueron: facilidad de uso, satisfacción de uso, conocimiento de la estructura de la lección, conocimiento de la longitud de la lección, conocimiento de la ubicación de los elementos de la lección, facilidad de navegación, comprensión de la lección y aprendizaje de la lección. Los resultados encontrados respaldan parcialmente la hipótesis del diseño emocional, que indica que los sentimientos positivos del usuario hacia la usabilidad de un sistema de e-learning pueden estar relacionadas positivamente con el aprendizaje del usuario.

La mayoría de los estudios publicados que evaluaron los efectos de los principios del diseño multimedia en estudiantes de nivel universitario como participantes involucrados, utiliza lecciones muy cortas (es decir, <3 minutos) y se llevaron a cabo en los laboratorios en 
condiciones muy controladas (Issa et al., 2011). Issa y cols. (Issa et al., 2011) realizaron su investigación con estudiantes de medicina en un entorno real de aula con contenidos que debían ser estudiados por los participantes durante 45 a 60 minutos. Los estudiantes en los cuales se utilizaron materiales que implementaban los principios del aprendizaje multimedia lograron mejoras significativas en la comprensión que los estudiantes que accedieron otros materiales. Esta es una de las pocas investigaciones encontradas en las cuales el acceso a los contenidos no se realiza en un laboratorio. 


\section{Descripción del desarrollo tecnológico}

El desarrollo tecnológico está compuesto de dos elementos: por una parte un sistema de administración de contenidos o ambiente virtual de aprendizaje y por otra parte los objetos virtuales de aprendizaje que incluyen lo materiales multimedia que deben ser estudiados.

\section{Los objetos virtuales de aprendizaje}

Los objetos virtuales de aprendizaje fueron elaborados en HTML5 con CSS3 y Jquery y empaquetados usando el estándar SCORM ya que es el estándar de eLearning con mayor penetración en el mercado educacional (Sayago, García, Griffiths, \& Blat, 2005).

Para el módulo experimental se realizaron dos paquetes SCORM, uno que incluía el material multimedia con señalización y otro sin señalización.

Los objetos virtuales de aprendizaje creados están divididos en páginas en las cuales se presenta la información. Las páginas pueden ser navegadas a través de los botones “anterior” y "siguiente" o mediante el uso de la tabla de contenido. Adicionalmente siempre se encuentra visible el número de página que está activa y el total de páginas disponibles.

Los contenidos objeto de señalización son contenidos presentados a través de combinaciones de texto e imagen. Un contenido con señalización muestra con un cambio de color (de negro a azul) en las palabras que se desean resaltar como se muestra en la

Figura 2. Para el objeto virtual sin señalización se utiliza la misma presentación de texto e imagen, pero no se realiza el cambio de color en el texto de mayor importancia dentro del contenido de la página. Un ejemplo de un contenido sin señalizar se muestra en la Figura 3.

Mediante programación en Jquery se lleva la cuenta de las páginas que contiene el módulo y qué páginas son visitadas, de esa forma se puede establecer cuando un participante ha visto todo el contenido de un objeto virtual de aprendizaje. 


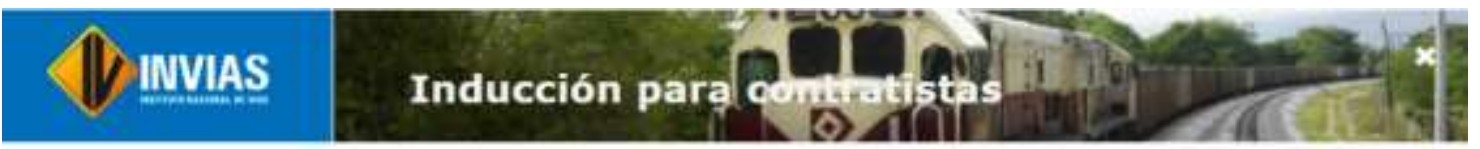

\section{INTRODUCCIÓN}

El Instituto Nacional de Vias, INVIAS, fue creado en 1992 e inició labores en el anio de 1994 y desde entonces se ha convertido en urio de los referentes de desarrolio nacional en materla de infraestructura.

En esta sección usted conocerd qué es INVIAS, cómo esta estructurado, cuales son los pincipios, valores y normas por los que se riqe y cualles sorn sus funciones.

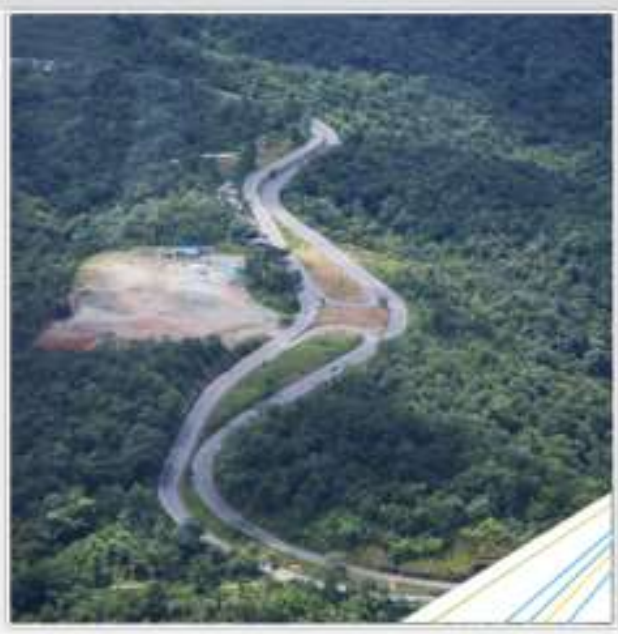

Conociendo el thetituto Nacional de Vias - IFVIAS

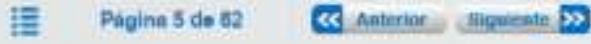

Figura 2 Presentación de una página con señalización

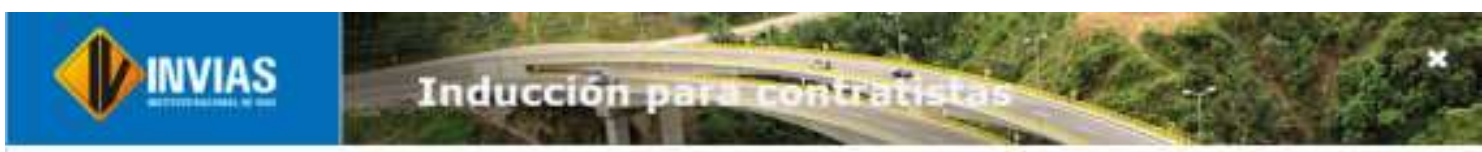

\section{INTRODUCCIÓN}

El tnstututo Nacional de Vias, INVIAS, fue creado en 1992 e iniciós labores en el atho de $1994 \mathrm{y}$ desde entonces se ha convertido en uno de los referentes def desarrollo nacional en materia de infraestructura.

En esta secrión usted conocerd que es INVIAS, cormo esta estructurado, cualles son los principios, valores y noimas por los que se rige y cuáles son sus funciones.

Conociendo ol inatinuto Nacional de Vias - INVIAS

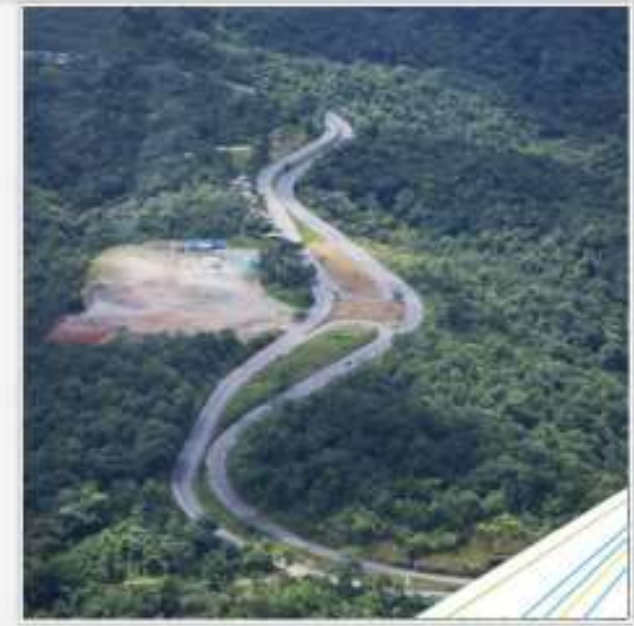

Figura 3 Presentación de una página sin señalización 


\section{El ambiente virtual de aprendizaje}

Para el ambiente virtual de aprendizaje se utilizó como base tecnológica una plataforma Moodle 2.9.1, la cual fue instalada sobre un servidor Linux con procesador Intel Xeon y 8 GB de Ram.

Se seleccionó la plataforma Moodle dado que sobresale en lo referente a alternativas de productividad, soporte, usabilidad, especificaciones técnicas, flexibilidad y sencillez (Valbuena \& Mora, 2013).

\section{Descripción del curso virtual para el administrador}

La interfaz de administración de Moodle es utilizada para crear un curso virtual. Dentro de la información de configuración del curso se elige el formato de temas para facilitar la publicación del material multimedia. El curso virtual fue dividido en cuatro temas, en cada uno de ellos se publica un objeto virtual de aprendizaje que corresponde a cada uno de los módulos que integran el temario del curso. Una vista del curso virtual se puede ver en el Anexo 2.

Únicamente el módulo dos, titulado: "Conociendo INVIAS" fue objeto de experimentación con señalización.

Para diferenciar gráficamente cada uno de los módulos dentro del curso virtual, se diseñó una imagen como la que se muestra en la Figura 4.

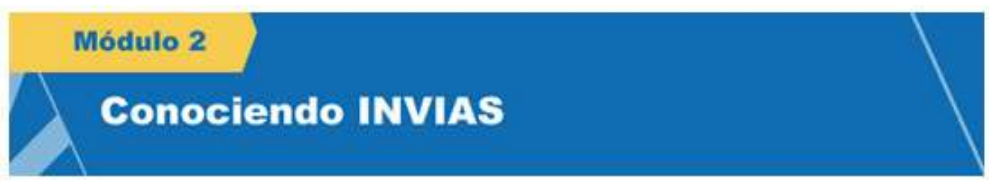

Figura 4 Imagen que identifica un módulo del curso virtual 
Bajo la imagen que identifica el módulo de estudio se añade una actividad de tipo SCORM, una actividad se añade para el grupo que tendrá señalización y otra para el grupo que no tendrá señalización. El paquete SCORM es configurado sin límite de intentos, por lo cual los participantes podrán interactuar con él las veces que lo requieran. En la Figura 5 se identifican con el ícono de caja amarilla los dos paquetes SCORM que fueron adicionados.

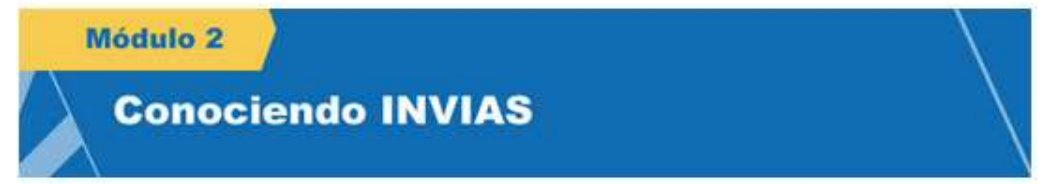

Estudie el material de este módulo. Una vez finalice la revisión del material, se habilitará el acceso a la evaluación del módulo.

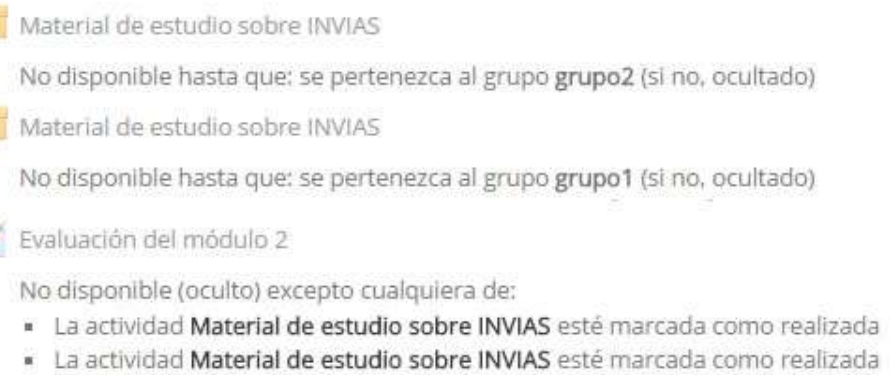

Figura 5 Vista de las actividades por parte del tutor del curso

Para que solo uno de los paquetes SCORM sea mostrado a cada participante dependiendo del grupo al cual fue asignado, se utilizan las opciones de configuración de restricción de acceso que ofrece Moodle. La configuración para el grupo sin señalización se muestra en la Figura 6.

\section{- Restricciones de acceso}

Restricciones de acceso

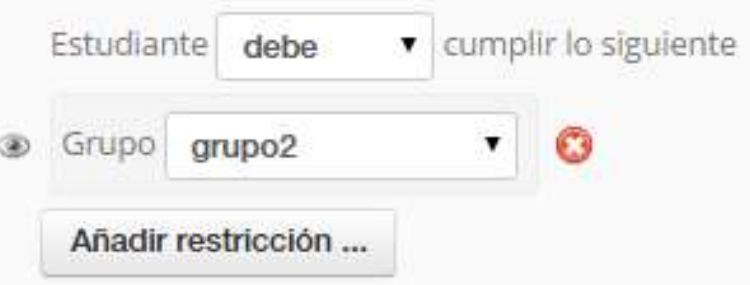

Figura 6 Configuración de la restricción de acceso a un contenido 
Teniendo en cuenta que es necesario que el participante vea todas las páginas de contenido antes de presentar la evaluación, se realiza la configuración de las opciones de finalización del paquete scorm como se muestra en la Figura 7. Si el objeto virtual de aprendizaje indica a la plataforma (a través de SCORM) que se ha visto todo el contenido, el estado cambia a “finalizado" y se cumpliría la condición necesaria para que se habilite la evaluación del módulo.

- Finalización de actividad

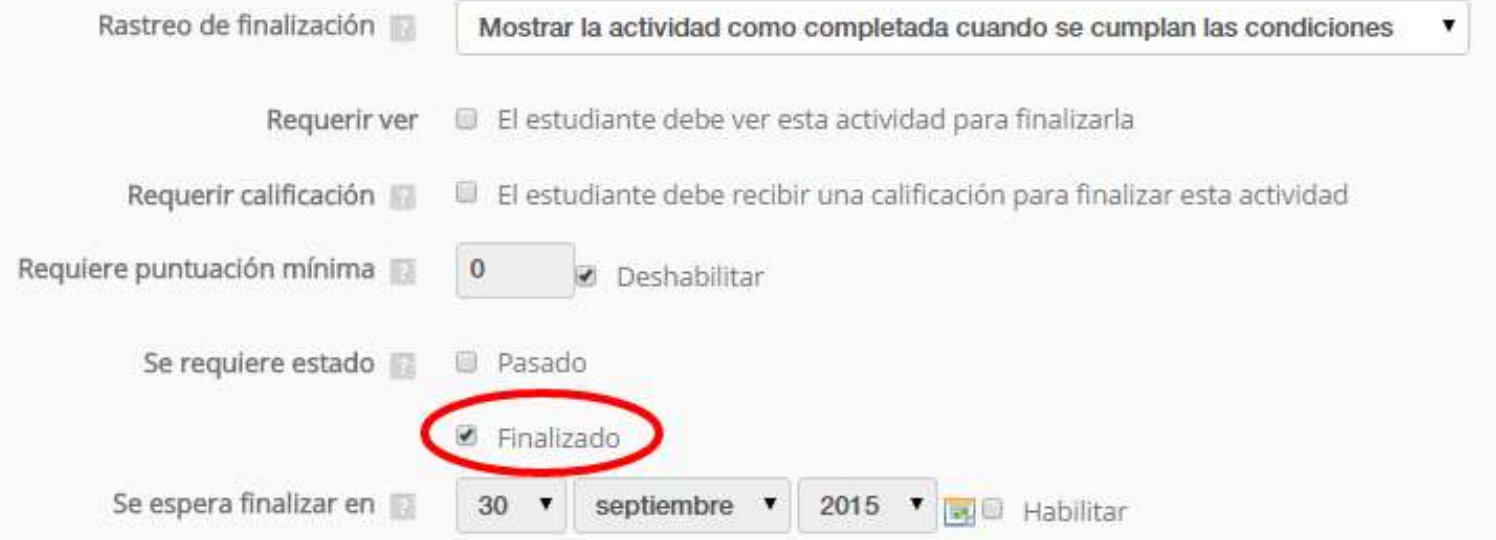

Figura 7 Configuración de las opciones de finalización de la actividad

\section{Descripción del curso virtual para el participante}

Para ingresar al aula virtual era requerido contar con un usuario y contraseña como se muestra en la Figura 8. A través de correo electrónico le fue notificado a cada participante la información de acceso al aula virtual, las instrucciones para iniciar sesión y los requerimientos técnicos necesarios para visualizar los contenidos. Los participantes tuvieron acceso al curso virtual durante un mes. 

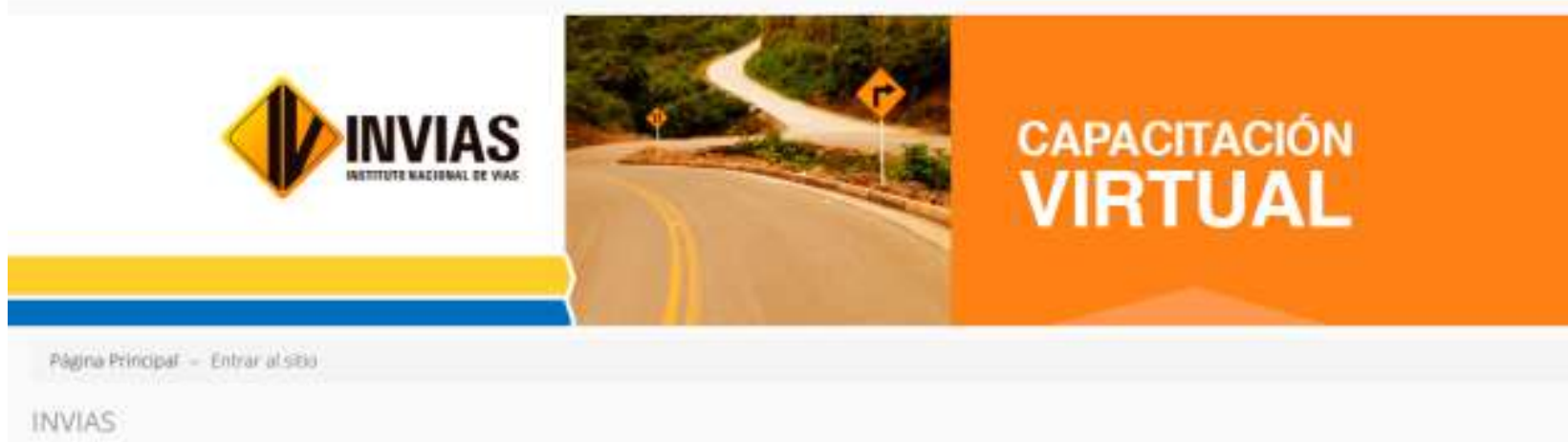

INVIAS

Entrar

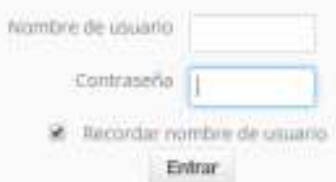

¿OQvido su numbere de usuano o contrusefial

Lat Cockies deben etar habiltadas en su navegader $\mathrm{E}$

Figura 8 Página de ingreso al aula virtual

Una vez se ingresa al aula virtual se encuentra la presentación del curso en la cual se describen los objetivos, la metodología, la forma de evaluación y los requisitos para aprobar el curso. Esta información es la misma para los dos grupos.

Cada una de las actividades del curso tiene a la derecha un ícono en forma de cuadrado que indica si una actividad ha sido finalizada o no. En la

Figura 9 se muestra cómo se ve el curso virtual cuando se ingresa por primera vez y las actividades no se han finalizado. 


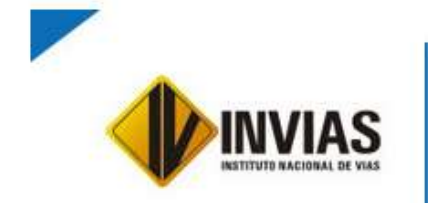

\section{Curso}

Inducción para contratistas

¡BIENVENIDO!

ANTES DE INICIAR EL ESTUDIO DE LOS MÓDULOS, LE INVITAMOS A VER LA PRESENTACIÓN GENERAL DEL CURSO.

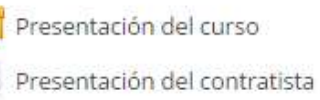

Figura 9 Visualización de actividades cuando no han sido finalizadas

Una vez se ha visualizado todo el contenido del módulo, se despliega a la derecha de la actividad una marca como la que se puede ver en la Figura 10, la cual indica que la actividad "Material de estudio sobre INVIAS" ha finalizado y por lo tanto la evaluación del módulo se encuentra disponible.

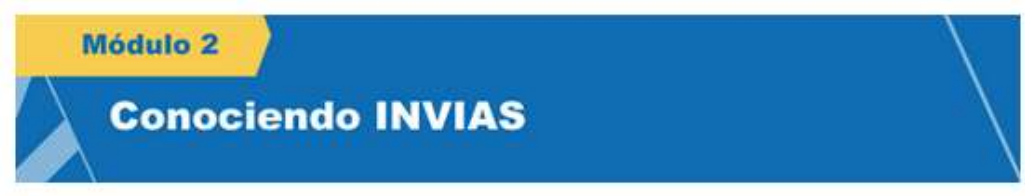

Estudie el material de este módulo. Una vez finalice la revisión del material, se habilitará el acceso a la evaluación del módulo.

Material de estudio sobre INVIAS

Evaluación del módulo 2

Figura 10 Visualización de actividades cuando han sido finalizadas

Cuando el usuario hace clic en la evaluación del módulo, se presenta un resumen de las condiciones que se configuraron en el cuestionario como se muestra en la Figura 11. 


\section{Evaluación del módulo 2}

Intentos permitidos; 3

Limite de tiempo: 30 minutos

Método de calificación: Calificación más alta

Intente resolver el cuestionario ahora

Figura 11 Página de introducción a la evaluación

Una vez el participante hace clic en el botón "Intente resolver el cuestionario ahora” se inicia un contador de tiempo en la parte izquierda de la pantalla como se muestra en la Figura 12.

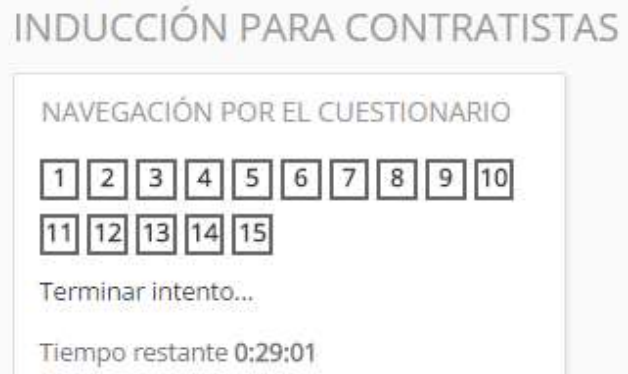

Figura 12 Contador de tiempo en la evaluación

En la parte derecha de la pantalla se desplegarán todas las preguntas del cuestionario, una debajo de la otra. En la Figura 13 se puede ver un ejemplo de una pregunta de selección múltiple con única respuesta.

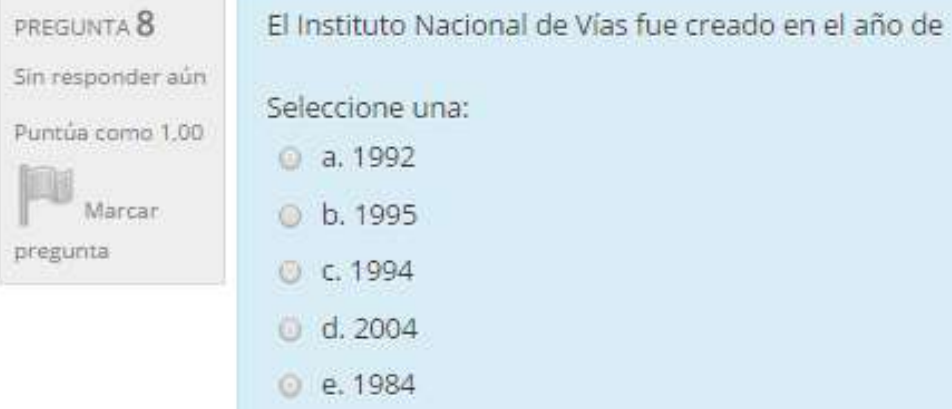

Figura 13 Pregunta de selección múltiple en la evaluación 


\section{Evaluación}

Para realizar la evaluación del módulo y la evaluación del curso virtual se utilizó la actividad tipo cuestionario que ofrece Moodle.

Se realizó la carga de un banco de preguntas para cada uno de los módulos. Las preguntas podían ser de tres tipos:

- Emparejamiento

- Selección múltiple (las opciones de respuesta se presentan de forma aleatoria)

- Falso / Verdadero

Una vez ingresadas todas las preguntas al banco de preguntas, se crea el cuestionario con una selección aleatoria de las preguntas. Dado que el banco de preguntas contiene más preguntas que las que se muestran en el cuestionario, esto implica que a todos los participantes no les salen las mismas preguntas. Las preguntas son seleccionadas de forma aleatoria similar a como lo realizan Ruf y Opwis (2014).

La evaluación que debe realizar el participante una vez finaliza el módulo está configurada para que se realice en un tiempo máximo de 30 minutos y se puede presentar hasta un máximo de 3 veces (en cada intento pueden salir preguntas diferentes). Entre intentos se exige una espera de mínimo 30 minutos. En caso de que el participante utilice varios intentos en la evaluación, la nota final será la del intento en el que obtuvo una mejor calificación. La evaluación solo se habilita si el participante ha navegado todas las páginas del contenido.

La evaluación final se debe presentar una vez el participante ha estudiado todos los módulos del curso (incluyendo el módulo experimental). La evaluación final también se crea como una actividad tipo cuestionario, se genera con 20 preguntas que son seleccionadas aleatoriamente del banco de preguntas de cada uno de los módulos (cinco preguntas por cada 
módulo). A diferencia de la evaluación del módulo, para esta evaluación solo se tiene un intento y cuarenta minutos. Con la evaluación final se busca realizar una segunda medición para verificar el efecto en el largo plazo (Amadieu et al., 2011; Ruf et al., 2014).

\section{Información inicial de los participantes}

Los participantes son creados con anterioridad en Moodle, se matriculan en el curso virtual y se asignan a un grupo dentro del curso, dependiendo del sorteo. Al crear los participantes se cuenta con la siguiente información: nombres, apellidos, documento de identidad, correo electrónico, lugar de trabajo (Planta central, Territorial), género (masculino, femenino), grupo asignado (con señalización, sin señalización).

La base de datos inicial de los participantes en el curso virtual no contaba con la información de la fecha de nacimiento o edad de cada uno de los usuarios, por lo cual se diseñó un formulario inicial al que se denominó "Presentación del contratista" para solicitarle al usuario información adicional como su edad.

Este formulario fue desarrollado con PHP 5.5 y la información almacenada en una base de datos mySQL 5. Para vincular el formulario en el curso virtual se creó un recurso tipo URL, en los parámetros del enlace se envía el documento de identidad del participante para posteriormente poder identificar a qué usuario pertenece cada dato almacenado.

La presentación del contratista se configura como una actividad opcional, por lo cual no tenía ninguna restricción de acceso y no era requisito para ninguna de las actividades posteriores. 


\section{Metodología}

\section{Participantes}

Ciento noventa contratistas de una entidad gubernamental participaron en el estudio. Los participantes tenían un contrato activo con la entidad para la vigencia 2015 y no habían tomado el curso de inducción a contratistas. Todos los participantes contaban con estudios de educación superior.

Datos de 121 participantes (59 hombres y 62 mujeres) fueron utilizados en el análisis ya que se tuvieron en cuenta solo los participantes que respondieron el cuestionario sobre la edad y que se clasifican como adultos económicamente activos (Martín Ruiz, 2005; Vásquez, 1985). La edad promedio de los participantes fue de 38.36 años $(\mathrm{SD}=10.24)$. La Tabla 2 presenta la cantidad de participantes por rango de edad.

Tabla 2. Participantes por rango de edad

\begin{tabular}{cc}
\hline Rango de edad & Número de participantes \\
\hline De 22 a 30 años & 33 \\
De 31 a 40 años & 42 \\
De 41 a 50 años & 26 \\
De 51 a 60 años & 20 \\
\hline
\end{tabular}

\section{Diseño}

El diseño corresponde a una investigación experimental, la asignación de los participantes a cada grupo se realizó de forma aleatoria. Al inicio se contaba con 190 participantes que fueron distribuidos entre dos grupos. La aleatorización de los participantes se realizó al iniciar la experimentación, momento en el cual no se contaba con la edad de los participantes. 
Una vez finalizada la experimentación, algunos usuarios no finalizaron la actividad, otros no compartieron su edad para este estudio y otros pocos no estaban dentro del rango de edad objeto de estudio por lo cual fueron retirados del análisis y la población quedó reducida a 121 participantes. En el grupo en que se aplicó el principio de señalización quedaron 54 participantes $(\mathrm{N}=54)$ y el otro grupo en el cual el contenido no se encontraba señalizado quedó conformado por 67 participantes $(\mathrm{N}=67)$.

\section{Interacción de los sujetos}

La interacción de los sujetos con la plataforma y los objetos virtuales de aprendizaje se desarrolla en cinco fases:

Fase 1: Familiarización con la plataforma. En esta primera fase el usuario recibe un correo electrónico de bienvenida al curso virtual el cual incluye un manual sobre cómo usar la plataforma. El usuario verifica que tiene acceso al aula virtual con el usuario y clave asignado e ingresa por primera vez a la plataforma.

Fase 2: Presentación del curso y del contratista. El participante debe revisar un objeto virtual en el cual se hace una breve presentación del curso, los objetivos, la metodología y la forma como será evaluado. Posteriormente el participante debe revisar el objeto virtual titulado "Presentación del contratista", a través de esta interacción del participante es que se obtiene la información de su edad. El acceso a este objeto virtual es voluntario.

Fase 3: Estudio de los contenidos. Para poder presentar las evaluaciones, el participante debe realizar el estudio de todos los contenidos. El acceso a los contenidos es libre, el estudiante puede realizar la revisión del material las veces que lo considere necesario. No hay límite de tiempo mínimo ni máximo exigido. 
Fase 4: Presentación de la evaluación inmediata. Una vez se finaliza la revisión del material del objeto virtual de aprendizaje, se habilita inmediatamente la evaluación del módulo estudiado. El participante tiene un máximo de 3 intentos para presentar la evaluación. La nota final del participante será la del mejor intento, pero para esta investigación se tiene en cuenta la información del primer intento.

Fase 5: Presentación de la evaluación final. Una vez el participante ha finalizado el estudio de todos los módulos del curso, se enfrenta a una evaluación final en la cual aparecen preguntas de todos los módulos, incluyendo el módulo experimental con señalización. Una vez presentada la evaluación final se calcula el puntaje total obtenido por el participante y se genera el certificado de participación en el curso (si obtuvo la nota mínima requerida para aprobarlo).

\section{Recolección de información}

Cuando se realizó el proceso de matriculación de usuarios se contaba con la información básica de cada uno de los participantes. Los participantes que voluntariamente accedieron a realizar la "Presentación del contratista" dejaron registrada en la base de datos su edad. 
Para cada paquete SCORM, la plataforma Moodle ofrece un reporte de acceso de cada uno de los participantes, registrando si la actividad se finalizó, si está incompleta o si no se ha realizado. Una vista de este reporte se puede encontrar en la Figura 14.

\begin{tabular}{|c|c|c|c|c|c|c|c|c|c|}
\hline \multicolumn{2}{|c|}{ Info } & \multicolumn{8}{|l|}{ Informes } \\
\hline \multicolumn{3}{|c|}{ Informe básico } & Informe gráfico & Informe de interacciones & \multicolumn{2}{|c|}{ Informe de objetivos } & & & \\
\hline \multicolumn{10}{|c|}{ 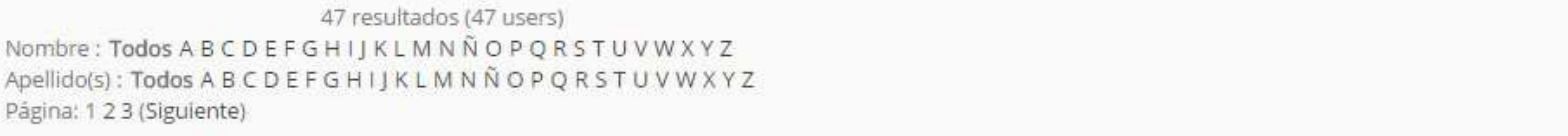 } \\
\hline & 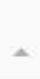 & Nombre & - / Apellido(s) & Dirección de correo & Intento & Comenzado en & Último acceso en & Puntuación & INVIAS \\
\hline b & ⿷ & ALEXAND & DER ENRIQUE & @invias.gov.co & 1 & $\begin{array}{l}\text { jueves, } 27 \text { de agosto } \\
\text { de } 2015,17: 31\end{array}$ & $\begin{array}{l}\text { Jueves, } 27 \text { de agosto } \\
\text { de } 2015,18: 42\end{array}$ & 0 & $\begin{array}{l}\text { Winalizado } \\
\text { Fing }\end{array}$ \\
\hline - & 鴊 & ANDREA & CAROLINA & @invias.gov.co & 1 & $\begin{array}{l}\text { lunes, } 14 \text { de } \\
\text { septiembre de } 2015 \text {, } \\
14: 11\end{array}$ & $\begin{array}{l}\text { lunes, } 14 \text { de } \\
\text { septiembre de } 2015 \text {, } \\
14: 16\end{array}$ & 0 & $\begin{array}{l}\text { Finalizado } \\
\text { Fin }\end{array}$ \\
\hline D & a & ANGELA & MARINA & @invias.gov.co & 1 & $\begin{array}{l}\text { martes, } 8 \text { de } \\
\text { septiembre de } 2015 \text {, } \\
09: 52\end{array}$ & $\begin{array}{l}\text { miércoles, } 9 \text { de } \\
\text { septiembre de 2015, } \\
\text { 13:21 }\end{array}$ & 0 & $\begin{array}{l}\text { Q } \\
\text { Finalizado }\end{array}$ \\
\hline D & 酯 & ARTURO & & & 1 & $\begin{array}{l}\text { viernes, } 2 \text { de octubre } \\
\text { de } 2015,13: 05\end{array}$ & $\begin{array}{l}\text { viernes, } 2 \text { de octubre } \\
\text { de } 2015,13: 30\end{array}$ & 0 & $\begin{array}{l}\text { On } \\
\text { Finalizado }\end{array}$ \\
\hline D & a & BLANCA & & @invias.gov.co & 1 & $\begin{array}{l}\text { martes, } 22 \text { de } \\
\text { septiembre de } 2015 \text {, } \\
17: 03\end{array}$ & $\begin{array}{l}\text { lunes, } 5 \text { de octubre } \\
\text { de } 2015,17: 59\end{array}$ & 0 & $\begin{array}{l}\square \\
\text { Incompleto }\end{array}$ \\
\hline
\end{tabular}

Figura 14 Reporte de acceso a un paquete SCORM

Del reporte de cada paquete SCORM se puede determinar para cada participante:

- Estado de visualización del contenido (sin revisar, incompleto, finalizado).

- Número de veces que se visitó el contenido

El número de visualizaciones se mide para determinar si la eficacia se incrementa con el número de exposiciones únicamente en la condición con señalización (Amadieu et al., 2011).

De forma similar, la plataforma genera un reporte de las calificaciones de los participantes en cada una de las evaluaciones. Dado que las preguntas se generaban aleatorias de un banco de 
preguntas existente y que se evaluaban varios temas a la vez, se determinó generar un indicador de eficiencia para cada evaluación.

Para cada participante se determinó el número de preguntas que le salieron correspondientes al módulo objeto de estudio, de esas preguntas cuántas tuvo correctamente y posteriormente se realizó el cálculo de la eficacia dividiendo el número de aciertos entre el número de preguntas.

Del proceso de evaluación se pudo obtener la siguiente información de cada participante:

- Eficacia en cada uno de los intentos

- Tiempo que tomó la presentación de cada evaluación

- Número de intentos realizados por cada estudiante en la evaluación

La información de las evaluaciones y de los accesos a los objetos quedaba almacenada en una base de datos. Posteriormente, la información fue exportada a una hoja de cálculo para su procesamiento en un programa estadístico.

\section{Resultados}

Todos los datos fueron procesados en el paquete estadístico SPSS 15.0 para Windows. La prueba estadística usada para comparar los grupos fue la prueba T para variables independientes, siendo la señalización (con / sin) la variable independiente.

Durante el análisis de resultados se tiene en cuenta la eficacia de los participantes en las pruebas de retención presentadas. La eficacia es un valor entre 0 y 1 y se calcula dividiendo el número de respuestas correctas del participante entre el número de preguntas que respondió. 
Para cumplir con los objetivos propuestos se realiza el análisis de las tres métricas importantes en este estudio: la eficacia en el primer intento (o medición inmediata), la eficacia en la evaluación final (medición pasado el tiempo) y el número de visualizaciones del objeto virtual de aprendizaje.

Eficacia en el primer intento. Al comparar los resultados de la eficacia en el primer intento, la prueba $\mathrm{T}$ arrojó que existen diferencias significativas entre el grupo que vio los contenidos con señalización y el grupo que los vio sin señalización (sig bilateral < 0.05). La eficacia del grupo con señalización tuvo un valor promedio de .9526, mientras que la eficacia promedio de los participantes que no tuvieron señalización fue de .8746 , lo cual deja ver que los participantes con señalización tuvieron mejores resultados. La Tabla 3 muestra los resultados de la prueba.

Tabla 3. Comparación de la eficacia en el primer intento

\begin{tabular}{cccccc}
\hline Grupo & N & Media & t & gl & Sig (bilateral) \\
\hline Con señalización & 54 & .9526 & 3.247 & 119 & 0.001 \\
Sin señalización & 67 & .8746 & 3.433 & 107.744 & \\
\hline
\end{tabular}

Este resultado permite cumplir con el primer objetivo de esta investigación que consiste en comparar la eficacia de un grupo que interactúa con un objeto virtual de aprendizaje señalizado y con otro que no.

Eficacia en la evaluación final. La evaluación final no se realiza inmediatamente se finaliza la revisión del módulo experimental, sino tiempo después, cuando el participante ha realizado todo el curso virtual. Al comparar los resultados de la eficacia en la evaluación final, la 
prueba T no arrojó diferencias significativas entre el grupo que vio los contenidos con señalización y el grupo que los vio sin señalización (sig bilateral > 0.05). La eficacia promedio del grupo que tenía señalización es de .94 mientras que el grupo que no tenía señalización tiene una eficacia promedio de .89. Aunque estadísticamente no hay diferencias entre los dos grupos, se puede observar que el valor del error estuvo muy cerca del 0.05 usado como referencia para determinar si hay diferencias y que los datos muestran mejores resultados para el grupo con señalización. La Tabla 4 muestra los resultados de la prueba.

Tabla 4. Comparación de la eficacia en la evaluación final

\begin{tabular}{cccccc}
\hline Grupo & N & Media & t & gl & Sig (bilateral) \\
\hline Con señalización & 45 & .94 & 1.357 & 100 & 0.057 \\
Sin señalización & 57 & .89 & 1.423 & 96.897 & \\
\hline
\end{tabular}

Solo 102 participantes culminaron el curso y presentaron la evaluación final durante la etapa de recolección de información. Los datos analizados revelan que los participantes aunque tenían un mes para realizar el curso, decidieron realizar todos los módulos en un mismo día y no realizar el estudio del curso distribuido en el tiempo. El tiempo promedio entre que se presentó la evaluación del módulo y la evaluación final es de 15 horas, al eliminar los casos extremos, la mayor parte de la población estudiada tiene un tiempo entre evaluaciones de 6 horas.

Este resultado permite cumplir con el segundo objetivo de la investigación ya que se pudo determinar que aunque la aplicación del principio de señalización no genera efectos con el paso del tiempo, los valores obtenidos estuvieron muy cerca del límite de error usado y se hace necesario realizar más pruebas para evidenciar el efecto de la señalización con el paso del tiempo. 
Para complementar el análisis se realizó una prueba de correlación bivariada entre el resultado de la evaluación realizada en el primer intento y la evaluación final para determinar si había alguna relación recíproca entre los dos resultados. En la Tabla 5 se puede ver que el análisis de correlación entre la eficacia del primer intento y la evaluación final no representa que exista una relación entre los dos resultados al tener una significancia mayor a 0.05.

Tabla 5. Correlación de la eficacia entre el primer intento y la evaluación final

\begin{tabular}{ccc}
\hline & & Eficacia evaluación final \\
\hline Eficacia primer intento & Correlación de Pearson & .159 \\
& Sig (bilateral) & .111 \\
$\mathrm{~N}$ & 102 \\
\hline
\end{tabular}

Múltiples visualizaciones. Se encontró que 52 participantes vieron el contenido una única vez mientras que 69 participantes realizaron múltiples vistas al contenido. Al analizar los resultados obtenidos se encuentra que no hay diferencias significativas en la eficacia de los participantes que vieron los contenidos una vez y quienes los vieron varias veces como se muestra en la Tabla 6.

Tabla 6. Eficacia en la evaluación inmediata según el número de visualizaciones

\begin{tabular}{lccccc}
\hline \multicolumn{1}{c}{ Grupo } & N & Media & t & gl & Sig (bilateral) \\
\hline $\begin{array}{l}\text { Eficacia en evaluación } \\
\text { inmediata }\end{array}$ & & & & & \\
Una visualización & 52 & .8983 & -0.779 & 119 & 0.437 \\
Múltiples visualizaciones & 69 & .9178 & -0.767 & 102.752 & \\
\hline
\end{tabular}

Se realizó un análisis por separado entre los participaciones con una vista única del contenido y quienes lo vieron varias veces para determinar si en cada segmento hubo alguna incidencia de la señalización en su eficacia. Entre los participantes que vieron el contenido 
únicamente una vez, si se encontraron diferencias entre el grupo con señalización y el grupo sin señalización en la eficacia del intento inmediato o primer intento y de la evaluación final.

En la Tabla 7 se muestran los resultados de los usuarios que vieron los contenidos una única vez. Se analizan por separado los efectos de la señalización en la prueba inmediata y en la evaluación final.

Para la prueba de retención realizada al momento de finalizar la revisión de los contenidos, la eficacia promedio del grupo con señalización que vio únicamente una vez los contenidos fue de .9690 mientras que para el grupo sin señalización, la eficacia promedio fue de .8541. El análisis estadístico muestra que las diferencias son significativas (sig bilateral < 0.05 ), lo cual muestra que la señalización favorece los resultados de los adultos en la prueba de retención. Los resultados son similares en la evaluación final, el grupo con señalización obtuvo una eficacia promedio de .97 y sin señalización la eficacia promedio fue de .82 (menor que la del primer intento), reforzando la hipótesis de que la señalización favorece la memoria de largo plazo.

Tabla 7. Eficacia en la evaluación cuando se vio el contenido una vez

\begin{tabular}{cccccc}
\hline Grupo & N & Media & t & gl & Sig (bilateral) \\
\hline Primer intento & & & & & \\
Con señalización & 20 & .9690 & 2.979 & 50 & 0.001 \\
Sin señalización & 32 & .8541 & 3.457 & 47.431 & \\
Evaluación final & & & & & \\
$\quad$ Con señalización & 16 & .97 & 1.888 & 41 & 0.029 \\
$\quad$ Sin señalización & 27 & .82 & 2.276 & 37.689 & \\
\hline
\end{tabular}


En la Tabla 8 se presentan los resultados del análisis estadístico cuando los usuarios han visualizado los contenidos varias veces. Aunque el primer intento se observa que el promedio de los participantes que veían el contenido señalizado era mejor, el resultado estadístico muestra que no hay diferencias significativas entre el grupo con señalización y el grupo sin señalización (sig bilateral > 0.05).

Para los usuarios que vieron los contenidos varias veces, no hay una diferencia significativa en términos estadísticos de los resultados de los usuarios que tenían señalización y los que no, sin embargo, se puede apreciar que en el primer intento la eficacia promedio de los estudiantes con señalización (.9429) es superior a los que no tenían señalización (.8934). Resultado similar se observa en la evaluación final en la cual la media del grupo con señalización (.93) es superior a la del grupo sin señalización (.85).

Tabla 8. Eficacia en la evaluación cuando se vio el contenido varias veces

\begin{tabular}{cccccc}
\hline Grupo & N & Media & t & gl & Sig (bilateral) \\
\hline Primer intento & & & & & \\
Con señalización & 34 & .9429 & 1.604 & 67 & 0.112 \\
Sin señalización & 35 & .8934 & 1.615 & 57.059 & \\
Evaluación final & & & & & \\
Con señalización & 16 & .93 & -0.443 & 57 & 0.659 \\
$\quad$ Sin señalización & 27 & .85 & -0.442 & 55.342 & \\
\hline
\end{tabular}

Estos resultados permiten cumplir con el tercer objetivo de la investigación que consistía en establecer si el número de visualizaciones del objeto virtual de aprendizaje incide en los resultados de la señalización. 
Aunque no estaba dentro de los objetivos de la investigación realizar comparaciones adicionales, se realizó una análisis con las variables de las cuales se tenía información para determinar si existía alguna diferencia al realizar comparaciones por género, número de intento en la evaluación y tiempo dedicado a la evaluación.

Intentos en la evaluación. Sólo 2 participantes utilizaron los tres intentos en la evaluación del módulo, 12 participantes utilizaron dos intentos y 107 participantes solo utilizaron el primer intento. Por lo cual, en las comparaciones solo se tuvo en cuenta la eficacia en el primero intento y la eficacia en la evaluación final. La eficacia en el segundo y tercer intento no fue tenida en cuenta en el análisis de resultados. Dado el bajo número de personas que utilizaron dos o más intentos, la muestra fue muy pequeña para realizar una comparación entre los dos grupos.

Tiempo en la evaluación. Al realizar las comparaciones del tiempo utilizado por los participantes para resolver el cuestionario del módulo en su primer intento, se encontró que no hay diferencias significativas en el tiempo que tomó a los participantes responder la evaluación cuando habían visto contenidos con señalización o sin señalización.

Género. La eficacia en el primer intento y en la evaluación final no presentó diferencias significativas entre los participantes del género femenino y del género masculino. 


\section{Discusión de los resultados}

El objetivo de este estudio es investigar los efectos de la señalización en el aprendizaje multimedia con una población adulta, en un ambiente virtual de aprendizaje y no en un ambiente de laboratorio (como lo hicieron las mayoría de las investigaciones estudiadas) y permitiendo al participante decidir el momento en el cual realiza la revisión de los contenidos y la presentación de las evaluaciones. El análisis de los resultados obtenidos se realiza en esta sección partiendo de las hipótesis que se formularon al iniciar la investigación.

La primera hipótesis formulada se refiere a que los estudiantes con señalización en el mensaje multimedia tienen mejores resultados en una prueba de conocimientos que los estudiantes a los que no se les presenta señalización. Esta hipótesis se sustenta en las investigaciones realizadas en los últimos diez años por diferentes investigadores en Estados Unidos, Europa y Asia cuyos resultados confirman el efecto de la señalización (Amadieu et al., 2011; Boucheix et al., 2013; De Koning et al., 2009; Doolittle \& Altstaedter, 2009; Jarodzka, van Gog, Dorr, Scheiter, \& Gerjets, 2013; Kriz \& Hegarty, 2007; Mautone \& Mayer, 2007; Moreno, 2007; Naumann et al., 2007; Ozcelik et al., 2010; Rey, 2012; Scheiter \& Eitel, 2015; Sung \& Mayer, 2012).

Las investigaciones estudiadas implementan la señalización en objetos de aprendizaje destinados a jóvenes estudiantes de pregrado con edades inferiores a 25 años (ver datos en Anexo 1) mientras que en esta investigación la población son adultos en edad productiva con un promedio de edad de 38 años. Otra diferencia importante entre esta investigación y las anteriores es que las investigaciones anteriores se realizaron en un ambiente de laboratorio, exceptuando el trabajo realizado por Issa y cols. (2011) que se realizó en un salón de clase. En esta investigación los participantes interactúan con el contenido en un aula virtual que acceden a través de Internet. 
Los resultados de la comparación de los dos grupos en la población adulta estudiada confirman que la aplicación del principio de señalización en textos estáticos puede ser beneficiosa para mejorar los resultados de una prueba de retención de igual forma a como sucede en otras investigaciones con personas más jóvenes (Boucheix \& Lowe, 2010 Exp. 1a; Issa et al., 2011; Jamet et al., 2008; Naumann et al., 2007; Ozcelik et al., 2009). Estos resultados permiten confirmar la primera hipótesis de esta investigación para la población estudiada.

Sin embargo, por ser el primer acercamiento a la señalización enfocada en una población adulta trabajadora, se hace necesario realizar más experimentos similares para establecer si se obtienen los mismos resultados, ya que se han encontrado investigaciones en las cuales la señalización genera un efecto inverso en los participantes (Boucheix \& Lowe, 2010 Exp. 1b; Jamet et al., 2008; Stull \& Mayer, 2007).

La segunda hipótesis de este estudio está relacionada con el efecto a largo plazo que puede presentar con la señalización. En investigaciones anteriores (Ruf et al., 2014; Schweppe \& Rummer, 2012) la aplicación de los principios del aprendizaje multimedia tenía un efecto positivo en los resultados tanto del corto plazo (inmediatamente se estudia el material) como en el largo plazo (una semana después), por eso para esta investigación se buscaba determinar si con el principio de señalización el efecto se lograba en el largo plazo como con otros principios.

Al analizar los resultados de la evaluación final presentada por los participantes de esta investigación se encuentra que no hay diferencias significativas en los participantes que usaron señalización y los que no usaron señalización. Los resultados indican que se deben realizar más investigaciones buscando determinar si esta situación es propia de la señalización o si los resultados se vieron afectados por la edad de los participantes de esta investigación o por el tiempo que pasó entre la presentación de la primera evaluación y la final. Por lo tanto la segunda hipótesis de este estudio no recibió evidencia empírica que la soporte. 
La tercera hipótesis de esta investigación hace referencia a las visualizaciones del contenido. Para Amadieu (2011), el puntaje se incrementó con el número de exposiciones únicamente en la condición con señalización, es decir, para este autor, no hubo diferencias entre señalización y no señalización cuando el objeto de aprendizaje se presentó una vez, pero si hubo diferencias en favor de la señalización cuando se presentaron múltiples exposiciones.

Los resultados de las pruebas realizadas en esta investigación ofrecen un efecto inverso al esperado. Cuando se presentan múltiples visualizaciones no hay diferencias significativas en los resultados en una prueba de retención para los participantes que se expusieron a la señalización frente a los que no tuvieron señalización. A su vez, en los participantes que realizaron la visualización del objeto virtual de aprendizaje una única vez si se encuentran diferencias con respecto a los que no tenían presencia de señalización. Todos los resultados de esta investigación no evidencian el cumplimiento de la hipótesis y al contrario, se oponen completamente a la hipótesis planteada y a los resultados de los estudios de Amadieu (2011).

Un aspecto que sobresale en el análisis y que establece un nuevo camino en el cual se debe profundizar la investigación es que se la señalización mostró efectos en el largo plazo para los participantes que vieron el contenido una sola vez. Para esta investigación se puede afirmar que se cumple la segunda hipótesis de que la señalización tiene un efecto en la memoria de largo plazo cuando los contenidos son vistos una única vez. Con esta condición, se generan resultados similares a otras investigaciones que estudiaron el efecto de los principios del aprendizaje multimedia en la memoria a largo plazo (Ruf et al., 2014; Schweppe \& Rummer, 2012). Para futuras investigaciones se hace necesario tener un tiempo mayor entre las dos evaluaciones ya que en esta investigación las diferencias fueron de horas y no de días como proponen los autores estudiados. 
En los datos analizados no es posible determinar si cuando los estudiantes realizaban una segunda visualización revisaban todo el material o navegaban a través de la tabla de contenido para llegar una parte específica del módulo, por lo cual se sugiere realizar investigaciones en la cual exista una medición más detallada de qué elementos del objeto virtual de aprendizaje son los que se examinan en cada visualización del material para poder determinar mejor la relación entre las visualizaciones realizadas y el efecto de la señalización. 


\section{Conclusiones y recomendaciones}

\section{Conclusiones}

Los adultos que interactuaron con un objeto virtual de aprendizaje que tenía señalización, obtuvieron mejores resultados en una prueba de conocimientos realizada inmediatamente después de que interactuaron con el objeto que los adultos que no tenían señalización en su objeto virtual de aprendizaje, mientras que en la prueba de conocimientos realizada un tiempo después no se encontraron diferencias, por lo tanto se concluye que la aplicación del principio de señalización en un objeto virtual de aprendizaje para la población estudiada incide en la memoria de corto plazo de los participantes.

La combinación entre múltiples visualizaciones al contenido y la implementación de señalización no ofrece diferencias en los resultados con respecto a un grupo que observe el contenido sin señalizar en múltiples ocasiones. Se puede inferir que el efecto de la señalización es equiparado por las múltiples visualizaciones del objeto virtual de aprendizaje, ya que ver el objeto varias veces puede permitir encontrar las ideas principales sin necesidad de que estas se encuentren señaladas.

Con una única visualización del objeto virtual de aprendizaje, la señalización tiene un efecto importante en la eficacia de los adultos que presentan una prueba de retención tanto en el corto como en el largo plazo. Los resultados de esta investigación fueron contrarios a los hallazgos de Amadieu y cols. (2011) quienes encontraron que múltiples visualizaciones favorecían el efecto de la señalización, mientras que con una única visualización no se encontraron diferencias en los resultados. La población de esta investigación al ser adultos profesionales que por su condición han desarrollado estrategias efectivas de aprendizaje pudieron retener mejor los conceptos tanto en el corto como en el largo plazo, lo que permitió que los dos 
grupos con y sin señalización se equipararan, es posible que al verlo señalizado los participantes no tuvieron que verlo nuevamente.

La señalización tiene un efecto tanto en el corto como en el largo plazo en los resultados de una pruebas de conocimientos presentada por adultos que estudiaron a través de un objeto virtual de aprendizaje, esto se evidencia principalmente en las personas que lo vieron una sola vez. En las personas que lo visualizaron varias veces, la señalización es suplida por el hecho de verlo varias veces porque de esa forma ayudó a mantener en la memoria los conocimientos adquiridos.

\section{Recomendaciones}

En este momento, es poco claro cuáles son las circunstancias en las cuales el uso de señalización será más efectiva en la educación virtual para adultos, por lo cual se presentan las siguientes recomendaciones:

Para futuras investigaciones sobre señalización se sugiere controlar el tiempo que debe pasar entre la primera y la segunda evaluación, para poder medir mejor los efectos de la señalización en la memoria de largo plazo.

Realizar un experimento en un aula virtual y no en un laboratorio como lo sugieren varios autores (Issa et al., 2011; McLaren et al., 2011b; Sung \& Mayer, 2012) aumenta el número de variables que se deben controlar durante la investigación, por lo tanto, estudiar sistemáticamente el valor de la señalización bajo diferentes circunstancias es esencial para una mejor comprensión de la señalización (De Koning et al., 2009).

Esta investigación se centró en realizar pruebas de retención para identificar que los participantes guiaban la atención hacia la información más relevante, se recomienda en futuras 
investigaciones con adultos estudiar el efecto de la señalización en pruebas de transferencia y de solución de problemas.

Existen pocas investigaciones que estudien los efectos de la señalización en la memoria de largo plazo, por lo cual los resultados acá obtenidos no pueden ser tenidos en cuenta para determinar las implicaciones en el aprendizaje de los adultos. Estos efectos deben ser estudiados en más investigaciones para determinar si hay diferencias entre jóvenes y adultos y si la señalización tiene efectos en la memoria de largo plazo.

Sería interesante estudiar el efecto en los resultados de los adultos cuando estudian a partir de animaciones que incluyen elementos de señalización (Amadieu et al., 2011; Boucheix et al., 2013; De Koning, Tabbers, Rikers, \& Paas, 2011). 


\section{Bibliografía}

Amadieu, F., Mariné, C., \& Laimay, C. (2011). The attention-guiding effect and cognitive load in the comprehension of animations. Computers in Human Behavior, 27(1), 36-40. http://doi.org/10.1016/j.chb.2010.05.009

Boucheix, J.-M., \& Lowe, R. K. (2010). An eye tracking comparison of external pointing cues and internal continuous cues in learning with complex animations. Learning and Instruction, 20(2), 123-135. http://doi.org/10.1016/j.learninstruc.2009.02.015

Boucheix, J.-M., Lowe, R. K., Putri, D. K., \& Groff, J. (2013). Cueing animations: Dynamic signaling aids information extraction and comprehension. Learning and Instruction, 25, 71-84. http://doi.org/10.1016/j.learninstruc.2012.11.005

Crooks, S. M., Cheon, J., Inan, F., Ari, F., \& Flores, R. (2012). Modality and cueing in multimedia learning: Examining cognitive and perceptual explanations for the modality effect. Computers in Human Behavior, 28(3), 1063-1071. http://doi.org/10.1016/j.chb.2012.01.010

De Koning, B. B., Tabbers, H. K., Rikers, R. M. J. P., \& Paas, F. (2007). Attention cueing as a means to enhance learning from an animation. Applied Cognitive Psychology, 21(6), 731746. http://doi.org/10.1002/acp.1346

De Koning, B. B., Tabbers, H. K., Rikers, R. M. J. P., \& Paas, F. (2009). Towards a Framework for Attention Cueing in Instructional Animations: Guidelines for Research and Design. Educational Psychology Review, 21(2), 113-140. http://doi.org/10.1007/s10648-0099098-7

De Koning, B. B., Tabbers, H. K., Rikers, R. M. J. P., \& Paas, F. (2010). Attention guidance in learning from a complex animation: Seeing is understanding? Learning and Instruction, 20(2), 111-122. http://doi.org/10.1016/j.learninstruc.2009.02.010 
De Koning, B. B., Tabbers, H. K., Rikers, R. M. J. P., \& Paas, F. (2011). Attention cueing in an instructional animation: The role of presentation speed. Computers in Human Behavior, 27(1), 41-45. http://doi.org/10.1016/j.chb.2010.05.010

Doolittle, P., \& Altstaedter, L. L. (2009). The Effect of Working Memory Capacity on Multimedia Learning: Does Attentional Control Result in Improved Performance? Journal of Research in Innovative Teaching, 2(1), 7-31.

Gagné, R. M. (1987). Las condiciones del aprendizaje. (Pecina, Jose Carmen, Trad.) (Tercera edición). Nueva Editorial Interamericana.

Ilgaz, H., Altun, A., \& Aşkar, P. (2014). The effect of sustained attention level and contextual cueing on implicit memory performance for e-learning environments. Computers in Human Behavior, 39, 1-7. http://doi.org/10.1016/j.chb.2014.06.008

Issa, N., Schuller, M., Santacaterina, S., Shapiro, M., Wang, E., Mayer, R. E., \& DaRosa, D. A. (2011). Applying multimedia design principles enhances learning in medical education. Medical Education, 45(8), 818-826. http://doi.org/10.1111/j.1365-2923.2011.03988.x

Jamet, E. (2014). An eye-tracking study of cueing effects in multimedia learning. Computers in Human Behavior, 32, 47-53. http://doi.org/10.1016/j.chb.2013.11.013

Jamet, E., Gavota, M., \& Quaireau, C. (2008). Attention guiding in multimedia learning. Learning and Instruction, 18(2), 135-145. http://doi.org/10.1016/j.learninstruc.2007.01.011

Jarodzka, H., van Gog, T., Dorr, M., Scheiter, K., \& Gerjets, P. (2013). Learning to see: Guiding students' attention via a Model's eye movements fosters learning. Learning and Instruction, 25, 62-70. http://doi.org/10.1016/j.learninstruc.2012.11.004 
Jeung, H.-J., Chandler, P., \& Sweller, J. (1997). The Role of Visual Indicators in Dual Sensory Mode Instruction. Educational Psychology, 17(3), 329-345. http://doi.org/10.1080/0144341970170307

Kalyuga, S., \& Renkl, A. (2009). Expertise reversal effect and its instructional implications: introduction to the special issue. Instructional Science, 38(3), 209-215. http://doi.org/10.1007/s11251-009-9102-0

Kriz, S., \& Hegarty, M. (2007). Top-down and bottom-up influences on learning from animations. International Journal of Human-Computer Studies, 65(11), 911-930. http://doi.org/10.1016/j.ijhcs.2007.06.005

Martín Ruiz, J. F. (2005). Los factores definitorios de los grandes grupos de edad de la población: tipos, subgrupos y umbrales. Scripta Nova: Revista electrónica de geografía y ciencias sociales, (9), 190-.

Mautone, P. D., \& Mayer, R. E. (2007). Cognitive aids for guiding graph comprehension. Journal of Educational Psychology, 99(3), 640-652. http://doi.org/10.1037/00220663.99.3.640

Mayer, R. E. (2002). Cognitive Theory and the Design of Multimedia Instruction: An Example of the Two-Way Street Between Cognition and Instruction. New Directions for Teaching and Learning, 2002(89), 55-71. http://doi.org/10.1002/t1.47

Mayer, R. E. (2008). Applying the science of learning: evidence-based principles for the design of multimedia instruction. The American Psychologist, 63(8), 760-769. http://doi.org/10.1037/0003-066X.63.8.760

Mayer, R. E. (2014). The Cambridge Handbook of Multimedia Learning (2 edition). Cambridge University Press. 
Mayer, R. E., \& DaPra, C. S. (2012). An embodiment effect in computer-based learning with animated pedagogical agents. Journal of Experimental Psychology. Applied, 18(3), 239252. http://doi.org/10.1037/a0028616

Mayer, R., \& Fiorella, L. (2014). Principles for Reducing Extraneous Processing in Multimedia Learning: Coherence, Signaling, Redundancy, Spatial Contiguity and Temporal Contiguity. En R. Mayer, The Cambridge Handbook of Multimedia Learning (2 edition, pp. 279-315). Cambridge University Press.

McLaren, B. M., DeLeeuw, K. E., \& Mayer, R. E. (2011a). A politeness effect in learning with web-based intelligent tutors. International Journal of Human-Computer Studies, 69(1-2), 70-79. http://doi.org/10.1016/j.ijhcs.2010.09.001

McLaren, B. M., DeLeeuw, K. E., \& Mayer, R. E. (2011b). Polite web-based intelligent tutors: Can they improve learning in classrooms? Computers \& Education, 56(3), 574-584. http://doi.org/10.1016/j.compedu.2010.09.019

Moreno, R. (2007). Optimising learning from animations by minimising cognitive load: cognitive and affective consequences of signalling and segmentation methods. Applied Cognitive Psychology, 21(6), 765-781. http://doi.org/10.1002/acp.1348

Moreno, R., \& Mayer, R. (2007). Interactive Multimodal Learning Environments. Educational Psychology Review, 19(3), 309-326. http://doi.org/10.1007/s10648-007-9047-2

Naumann, J., Richter, T., Flender, J., Christmann, U., \& Groeben, N. (2007). Signaling in expository hypertexts compensates for deficits in reading skill. Journal of Educational Psychology, 99(4), 791-807. http://doi.org/10.1037/0022-0663.99.4.791

OBS Business School. (2015). Informe OBS Business School E-learning II, Indicadores y tendencias 2015. (No. 2). Recuperado a partir de http://www.obs- 
edu.com/noticias/estudio-obs/espana-5o-pais-del-mundo-con-mas-estudiantes-de-moocsen-el-creciente-mercado-del-e-learning/

Orjuela, G. C. (2012). Observatorio del Mercado de Trabajo. Colombia: Ministerio del Trabajo.

Ozcelik, E., Arslan-Ari, I., \& Cagiltay, K. (2010). Why does signaling enhance multimedia learning? Evidence from eye movements. Computers in Human Behavior, 26(1), 110117. http://doi.org/10.1016/j.chb.2009.09.001

Ozcelik, E., Karakus, T., Kursun, E., \& Cagiltay, K. (2009). An eye-tracking study of how color coding affects multimedia learning. Computers \& Education, 53(2), 445-453. http://doi.org/10.1016/j.compedu.2009.03.002

Rey, G. D. (2012). A review of research and a meta-analysis of the seductive detail effect. Educational Research Review, 7(3), 216-237. http://doi.org/10.1016/j.edurev.2012.05.003

Ruf, A. P., Seckler, M., \& Opwis, K. (2014). Long-term Modality Effect in Multimedia Learning. En Proceedings of the 8th Nordic Conference on Human-Computer Interaction: Fun, Fast, Foundational (pp. 963-966). New York, NY, USA: ACM. http://doi.org/10.1145/2639189.2670251

Sayago, S., García, R., Griffiths, D., \& Blat, J. (2005). La aportación de IMS Learning Design a la creación de recursos pedagógicos reutilizables. RED: Revista de Educación a Distancia, (5), 1-.

Scheiter, K., \& Eitel, A. (2015). Signals foster multimedia learning by supporting integration of highlighted text and diagram elements. Learning and Instruction, 36, 11-26. http://doi.org/10.1016/j.learninstruc.2014.11.002

Schnotz, W. (2014). Integrated Model of Text and Picture Comprehension. En The Cambridge Handbook of Multimedia Learning (2 edition, pp. 72-103). Cambridge University Press. 
Schweppe, J., \& Rummer, R. (2012). Long-term Multimedia Learning (pp. 196-198). Presentado en In Staging Knowledge and Experience: How to Take Advantage of Representational Technologies in Education and Training?, E. Vries.

Stull, A. T., \& Mayer, R. E. (2007). Learning by doing versus learning by viewing: Three experimental comparisons of learner-generated versus author-provided graphic organizers. Journal of Educational Psychology, 99(4), 808-820. http://doi.org/10.1037/0022-0663.99.4.808

Sung, E., \& Mayer, R. E. (2012). Affective impact of navigational and signaling aids to elearning. Computers in Human Behavior, 28(2), 473-483. http://doi.org/10.1016/j.chb.2011.10.019

Tendencias y desafíos para el e-learning en 2015. (2015). América Learning \& Media, 36. Recuperado a partir de http://www.americalearningmedia.com/edicion-035/395tendencias/6201-tendencias-y-desafios-para-el-e-learning-en-2015

Twyford, J., \& Craig, S. (2013). Virtual Humans and Gesturing during Multimedia Learning: An Investigation of Predictions from the Temporal Contiguity Effect. En T. Bastiaens \& G. Marks (Eds.), Proceedings of World Conference on E-Learning in Corporate, Government, Healthcare, and Higher Education 2013 (pp. 2145-2149). Las Vegas, NV, United States: AACE. Recuperado a partir de http://www.editlib.org/p/115197

Valbuena, S. J., \& Mora, V. C. (2013). Comparativo entre los sistemas de gestión de aprendizaje Moodle y Maat Gknowledge. INGE CUC, 9(1), 183-195.

van Gog, T. (2014). The Signaling (or Cueing) Principle in Multimedia Learning. En R. Mayer, The Cambridge Handbook of Multimedia Learning (2 edition, pp. 263-278). Cambridge University Press.

Vásquez, E. M. (1985). Principios y técnicas de educación de adultos. EUNED. 


\section{Anexos}

\section{Anexo 1 Investigaciones en señalización}

Tabla 9. Investigaciones en señalización entre 2007 - 2015 por país de origen

\begin{tabular}{|c|c|}
\hline País(es) de origen & Edad promedio (SD) \\
\hline (1) Alemania (Scheiter \& Eitel, 2015) & $24.07(\mathrm{SD} 4.09)$ \\
\hline (2) Francia (Jamet, 2014) & $22.4(\mathrm{SD} 2.11)$ \\
\hline (3) Turquía (Ilgaz, Altun, \& Aşkar, 2014) & Pregrado \\
\hline (4) Holanda, Estados Unidos, Alemania (Jarodzka et al., 2013) & $22.83(\mathrm{SD} 4.04)$ \\
\hline (5) Francia, Australia, Indonesia (Boucheix et al., 2013) & $19.1(\mathrm{SD} 1.16)$ \\
\hline (6) Corea del Sur, Estados Unidos (Sung \& Mayer, 2012) & $23.36(\mathrm{SD} 2.19)$ \\
\hline (7) Estados Unidos (Crooks et al., 2012) & 19.52 \\
\hline (8) Holanda (De Koning et al., 2011) & $19.98(\mathrm{SD} 3.48)$ \\
\hline (9) Francia (Amadieu et al., 2011) & $22.6($ SD 5.42$)$ \\
\hline (10) Estados Unidos (Issa et al., 2011) & Tercer año de medicina \\
\hline (11) Turquía (Ozcelik et al., 2010) & $21.63(\mathrm{SD} 1.28)$ \\
\hline (12) Francia, Australia (Boucheix \& Lowe, 2010) & $20.7(\mathrm{SD} 3.27)$ \\
\hline (13) Turquía (Ozcelik et al., 2009) & $19.45(\mathrm{SD} 2.9)$ \\
\hline (14) Estados Unidos (Doolittle \& Altstaedter, 2009) & 19.4 \\
\hline (15) Francia (Jamet et al., 2008) & $21.9(\mathrm{SD} 1.2)$ \\
\hline (16) Estados Unidos (Moreno, 2007) & $25.29(\mathrm{SD} 8.14)$ \\
\hline (17) Estados Unidos (Kriz \& Hegarty, 2007) & Pregrado \\
\hline (18) Estados Unidos (Mautone \& Mayer, 2007) & Pregrado \\
\hline (19) Alemania (Naumann et al., 2007) & $25.4(\mathrm{SD} 6.5)$ \\
\hline (20) Estados Unidos (Stull \& Mayer, 2007) & $19.4(\mathrm{SD} 1.5)$ \\
\hline
\end{tabular}




\section{Anexo 2 Visualización del curso virtual en Moodle}

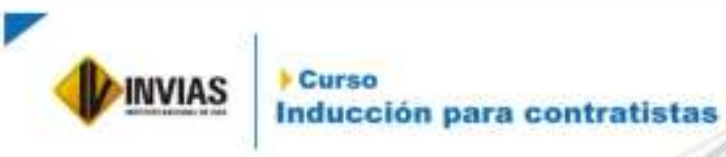

(Henverabo

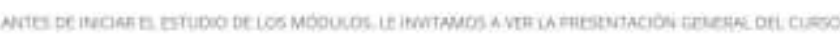

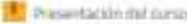

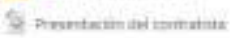

Matulato 1

Estructura del Estado Colomblano

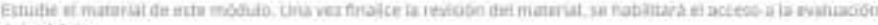
dei moduip

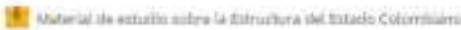

$\checkmark$ indiaculo ar inditio:

Moctuie 2

Conociendo INVIAS

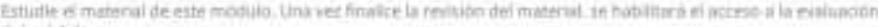
itei mintivilo

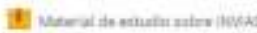

$\checkmark$ teviocinaed inosule?

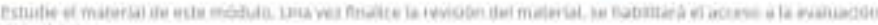
der mètus

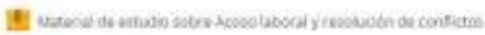

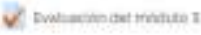
ifeit imotiale

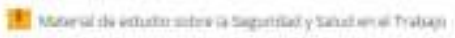

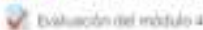

Figura 15 Visualización del curso virtual en Moodle 